Avaliação do estado de assoreamento do reservatório de Cachoeira Dourada (GO/MG) João Batista Pereira Cabral, Luiz Alberto Fernandes, Iraci Scopel, Valter Antonio Becegato, Alberto Pio Fiori

\title{
AVALIAÇÃO DO ESTADO DE ASSOREAMENTO DO RESERVATÓRIO DE CACHOEIRA DOURADA (GO/MG)*
}

\section{Evaluation of Sedimentation State in Cachoeira Dourada Reservoir (GO/MG), Brazil}

João Batista Pereira Cabral

Prof. Dr. Departamento de Geografia

Campus Jataí/Universidade Federal de Goiás

Jataí/GO - Brasil

jbcabral2000@yahoo.com.br

\section{Luiz Alberto Fernandes}

Prof. Dr. Departamento de Geologia

Universidade Federal do Paraná

Curitiba/PR - Brasil

lufernandes@ufpr.br

Iraci Scopel

Prof. Dr. Departamento de Geografia Campus Jataí/Universidade Federal de Goiás

Jataí/GO - Brasil iraciscopel@gmail.com

Valter Antonio Becegato

Prof. Dr. Departamento de Engenharia Ambiental Universidade do Estado de Santa Catarina

Lages/SC - Brasil becegato@udesc.br

Alberto Pio Fiori

Prof. Dr. Departamento de Geologia Universidade Federal do Paraná Curitiba/PR - Brasil fiori@ufpr.br

Artigo recebido para publicação em 23/04/2008 e aceito para publicação em 29/09/2008

RESUMO: Analisou-se o estado de assoreamento do reservatório de Cachoeira Dourada, da bacia do rio Paranaíba. Na investigação foram avaliados sedimentos de fundo do lago de $74 \mathrm{~km}^{2}$. Consideraram-se parâmetros granulométricos e batimétricos. Os resultados, apresentados em mapas, mostraram a distribuição dos

\footnotetext{
* Parte da tese do primeiro autor apresentada junto ao programa de Pós-Graduação em Geologia da UFPR em Outubro de 2006.
} 
Avaliação do estado de assoreamento do reservatório de Cachoeira Dourada (GO/MG)

João Batista Pereira Cabral, Luiz Alberto Fernandes, Iraci Scopel, Valter Antonio Becegato, Alberto Pio Fiori

parâmetros granulométricos e permitiram ainda estimar o volume do material sedimentado Os depósitos de fundo são constituídos essencialmente de: silte e argila no setor próximo ao barramento; de material arenoso fino a muito fino no setor médio do reservatório e, no setor à montante, tem-se desde silte até areia grossa. Pela comparação dos dados topográficos da época da construção do reservatório com os dados batimétricos medidos, o reservatório da usina de Cachoeira Dourada perdeu 38,5\% de sua capacidade de armazenamento original. A expectativa de vida útil da represa, estimada nesta pesquisa, a continuar o atual ritmo de assoreamento é de aproximadamente 145 anos.

Palavras-chave: Sedimentação. Reservatório. Rio Paranaíba

ABSTRACT: This research analyzed the degree of sedimentation in Cachoeira Dourada reservoir Brazil, belonging to the Paranaiba hydrologic catchment basin. Were evaluated bottom sediments of the lake, in an area of $74 \mathrm{~km}^{2}$. Were considered particle and bathymetric parameters. The results, presented on the maps, showed the distribution of the particles chacteristics and allowed to estimate the volume of sediments. The bottom deposits are essentially constituted of silt and clay in the portion near the dike; of fine and very fine sandy material in the middle sector of the reservoir and, in the beginning of the reservoir, we have since silt just large sand. By comparison of topographic data, since the construction of the reservoir, with present measured bathymetric data, the Cachoeira Dourada reservoir lost $38.5 \%$ of its original storing capacity. The expected reservoir useful life, estimated in this research, is of about 145 years, following this deposition rhythm.

Keywords: Sedimentation. Reservoir. River Paranaíba.

\section{Introdução}

A demanda energética, em constante aumento, tem sido o motivo principal para a construção de grandes reservatórios destinados à produção de energia elétrica no Brasil. Todavia, se mal geridas, tais obras têm seu tempo de vida útil reduzido pelo processo de assoreamento dos reservatórios, implicando na diminuição do volume de água utilizável e como consequência direta, reduz a quantidade de energia gerada.

A retenção de material particulado no lago, pela redução no regime de fluxo, é inevitável, porém, o assoreamento é um processo passível de ser administrado e reduzido. Nas últimas décadas desenvolveram-se estudos relacionados ao assoreamento de reservatórios de usinas hidrelétricas, visando sua manutenção e redução de perda de vida útil.
$\mathrm{Na}$ atualidade, um grande número de reservatórios brasileiros encontram-se total ou parcialmente assoreados, principalmente os de pequeno e médio portes (CARVALHO, 2000; CARVALHO et al, 2000).

O reservatório de Cachoeira Dourada foi escolhido para o estudo do assoreamento pelo fato de contemplar os objetivos do trabalho e ser relativamente pequeno em extensão e armazenamento de água, considerando-se o complexo de barragens construídas ao longo do rio Paranaíba, o que reduz e simplifica o volume de trabalhos. O reservatório situase a jusante daqueles de Itumbiara e Emborcação. Outro motivo da escolha é por constituir-se no único reservatório daquele rio que opera a fio d'água. Sua profundidade média, ao redor de $15 \mathrm{~m}$, permite a obtenção de perfis verticais com equipamento de mergulho autônomo.

Sociedade \& Natureza, Uberlândia, 21 (1): 97-119, ABR. 2009 
Avaliação do estado de assoreamento do reservatório de Cachoeira Dourada (GO/MG) João Batista Pereira Cabral, Luiz Alberto Fernandes, Iraci Scopel, Valter Antonio Becegato, Alberto Pio Fiori

Neste contexto, este trabalho pretendeu embasar recomendações para adoção de medidas mitigadoras em relação ao assoreamento do reservatório. Analisaram-se, de forma integrada, os processos erosivos e sedimentológicos e procurou-se determinar os principais locais de aporte de sedimentos. Esses dados são muito úteis para o planejamento e gerenciamento futuro dos recursos hídricos e hidrelétricos da bacia do rio Paranaíba.

\subsection{Localização da área de estudo e aspectos físicos da bacia hidrográfica}

A bacia hidrográfica da Usina Hidrelétrica (UHE) de Cachoeira Dourada (GO/MG) corresponde ao trecho do médio Paranaíba, localizado na divisa entre os estados de Goiás e Minas Gerais. Situa-se entre as coordenadas de $7910000 \mathrm{~m}$ e $8040100 \mathrm{~m}$ de latitude Sul, e $650000 \mathrm{~m}$ e $750500 \mathrm{~m}$ de longitude W, na carta de Cachoeira Dourada, na escala 1:100.000 (Fig. 1).

O reservatório foi construído em 1959, como parte do complexo de barragens da bacia do rio Paranaíba, com a finalidade principal de gerar energia elétrica. Seu lago foi planejado para um volume total de $519 \times 10^{6} \mathrm{~m}^{3}$, e a bacia de drenagem abrange área de $5.111 \mathrm{~km}^{2}$.

Os solos da área de estudo, típicos das regiões tropicais, são muito intemperizados e possuem baixa fertilidade natural. Predominam os Latossolos com horizonte "A", moderado ou proeminente, de textura argilosa ou muito argilosa.

O substrato rochoso (Fig. 2) da bacia hidrográfica, na área de estudo, é constituído por diversos tipos de rochas e seus produtos de alteração como: basaltos da Formação Serra Geral (Cretáceo
Inferior), Grupo São Bento; arenitos das formações Vale do Rio do Peixe (FVRP) e Marília, Grupo Bauru, depositadas no Cretáceo Superior; e rochas graníticas e gnáissicas do embasamento arqueano.

O relevo da área de estudo é constituído por formas de dissecação tabulares com elevações de topo plano, com diferentes ordens de grandeza, formando um conjunto de feições complexas. A área da bacia apresenta sulcos controlados por estruturas tectônicas, bordas escarpadas em alcantis com reversos em rampas de baixa declividade, geralmente interrompidas por relevos residuais de topos tabulares e níveis topográficos embutidos na superfície geral dos planaltos.

As áreas com relevos residuais correspondem aos morros "testemunhos" areníticos da Formação Marília. Esses arenitos são agregados por cimento de carbonato de cálcio e/ou argilas, o que lhes conferem maior resistência em relação ao intemperismo e à erosão (IBGE 1983; LATRUBESSE et al, 2004).

O clima dominante na área de estudo, segundo a classificação de Köppen, é do tipo Cwa, ou seja, quente e úmido, com estação chuvosa no verão e seca no inverno, com temperatura média anual entre $22^{\circ}$ $\mathrm{C}$ e $24^{\circ} \mathrm{C}$ e máxima podendo ultrapassar $35^{\circ} \mathrm{C}$.

A precipitação anual oscila entre 1200 e 1600 $\mathrm{mm}$, concentrando-se entre outubro e abril (estação chuvosa). As médias mensais, nesse período, variam de 100 a $350 \mathrm{~mm}$, enquanto na estação seca (abril a setembro), o índice pluviométrico varia de 0 a 100 $\mathrm{mm}$, o que caracteriza o período de deficiência hídrica e de temperaturas mais baixas (SCOPEL \& ASSUNÇÃO, 1999; SECTEC, 2000; CABRAL et al, 2005). 


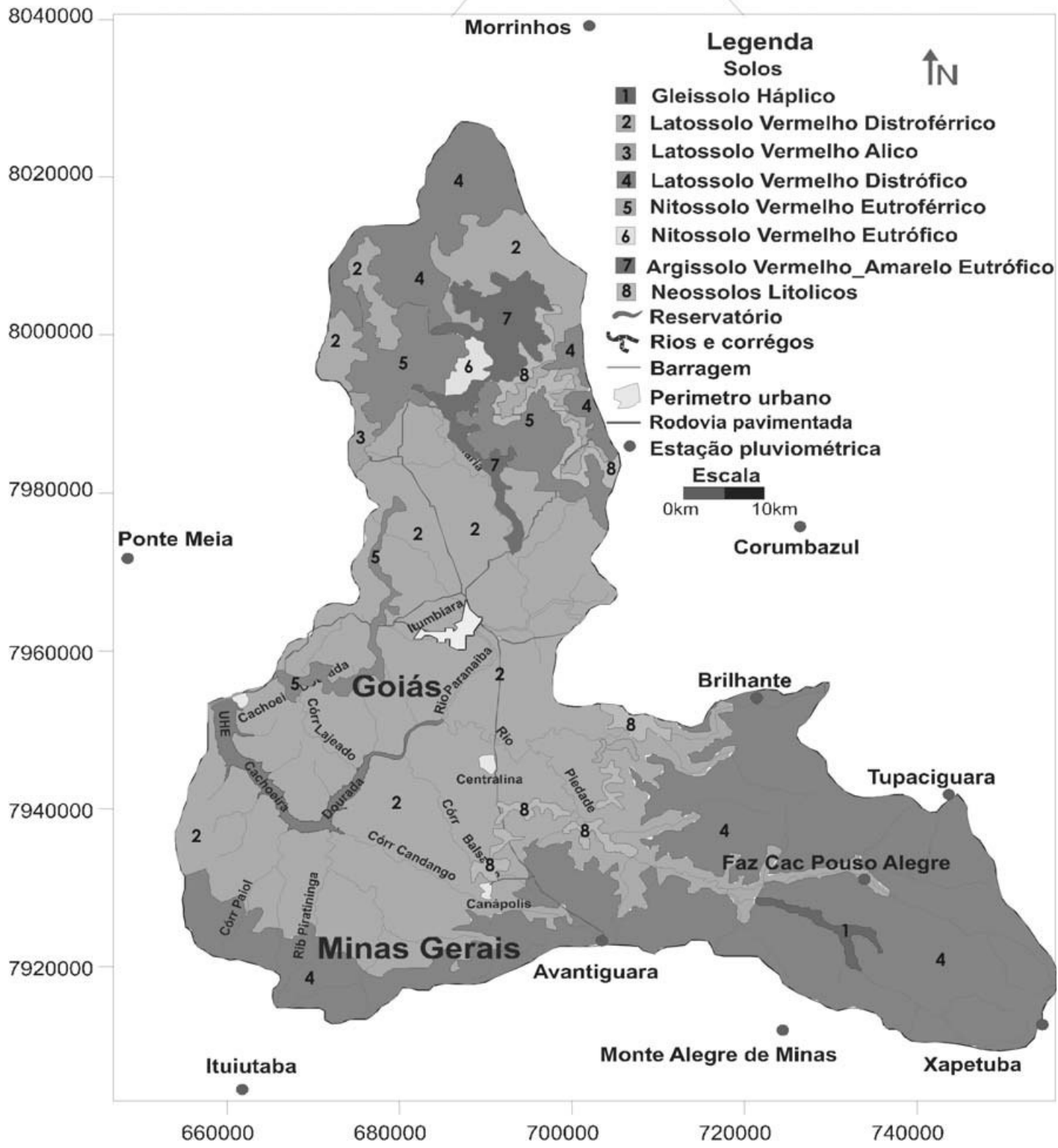

Figura 1. Mapa de classes de solos da área de estudo, adaptado da carta do estado de Goiás (SIG-GOIAS, 2003) 
Avaliação do estado de assoreamento do reservatório de Cachoeira Dourada (GO/MG) João Batista Pereira Cabral, Luiz Alberto Fernandes, Iraci Scopel, Valter Antonio Becegato, Alberto Pio Fiori

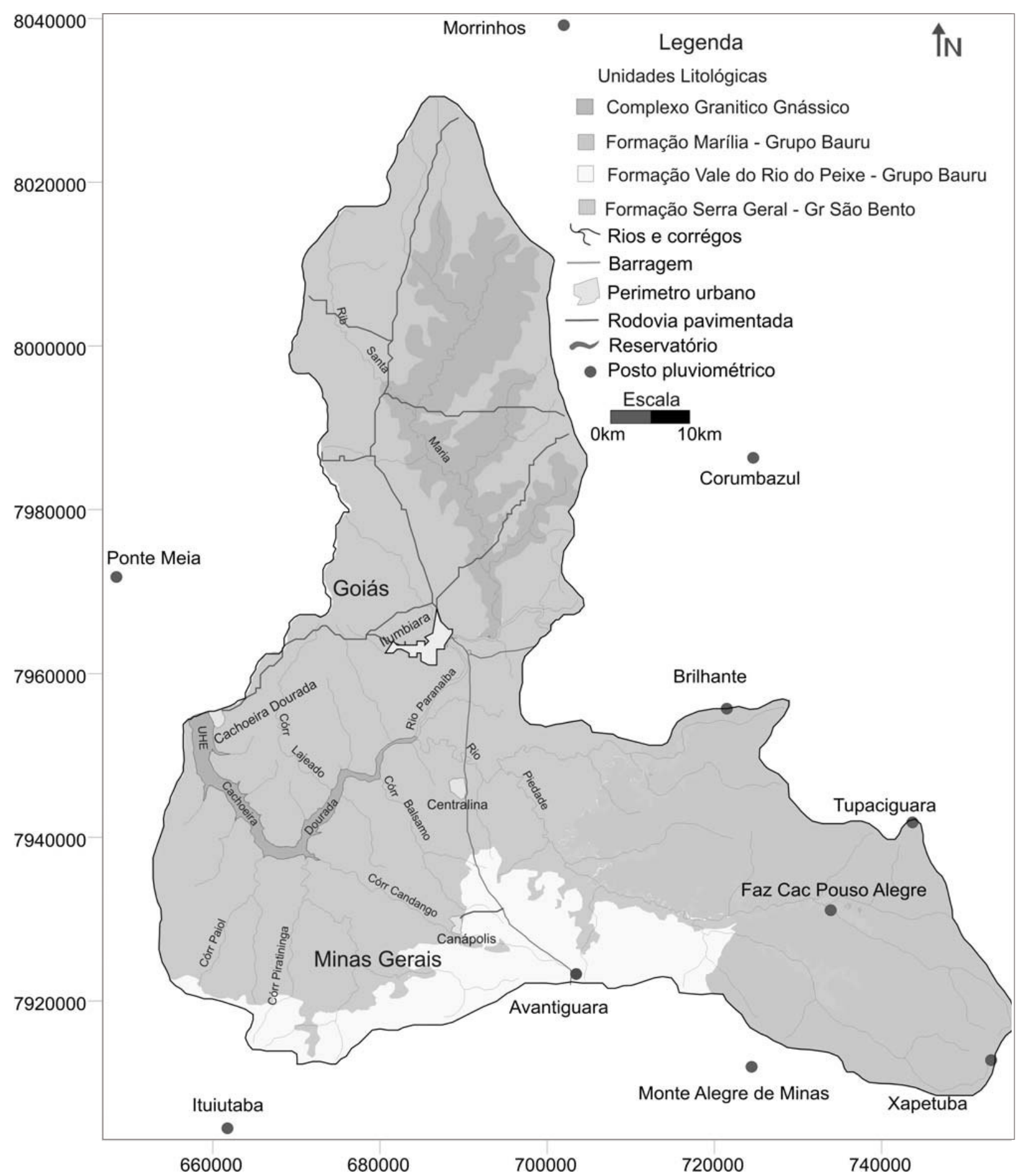

Figura 2. Mapa geológico da área de estudo, adaptado da Agência Goiana de Indústria e Mineração - Companhia de Pesquisa de Recursos Minerais (2002). 


\section{Material e métodos}

\subsection{Amostragem e caracterização dos sedimentos de fundo}

A amostragem da porção superficial dos depósitos de fundo foi efetuada com amostrador tipo "draga de Peterson". A análise granulométrica dos sedimentos foi realizada por peneiramento e pipetagem, conforme descrito em Suguio (1973). O material sedimentado foi classificado segundo escala de Wentworth (1922).

Nos cálculos dos parâmetros estatísticos foram usadas as fórmulas propostas por Krumbein (1934) e Folk e Ward (1957), efetuados com uso do

A)

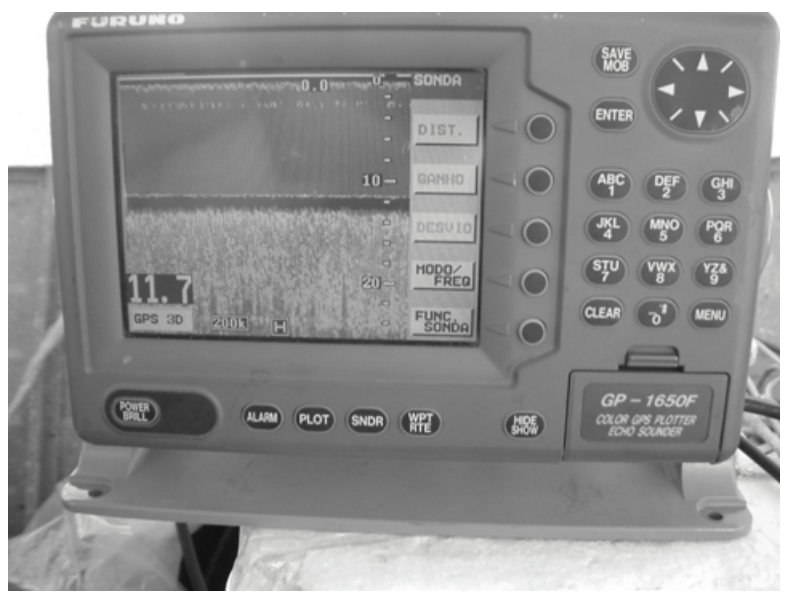

programa Sysgran, desenvolvido por Camargo (1999). Ao todo, foram analisadas 33 amostras da campanha de 2003 e 37 em 2005.

\subsection{Levantamento batimétrico e estimativa do volume do material do assoreamento}

O equipamento utilizado para a batimetria era constituído por uma ecossonda modelo Furuno GP1650F e um Sistema de Posicionamento Global (GPS), acoplados a um computador (Fig. 3A e B). O software Fugawi 3 realizou o processamento do sinal e o armazenamento dos dados, os quais puderam ser exportados em formato de quadros para outros softwares.

B)

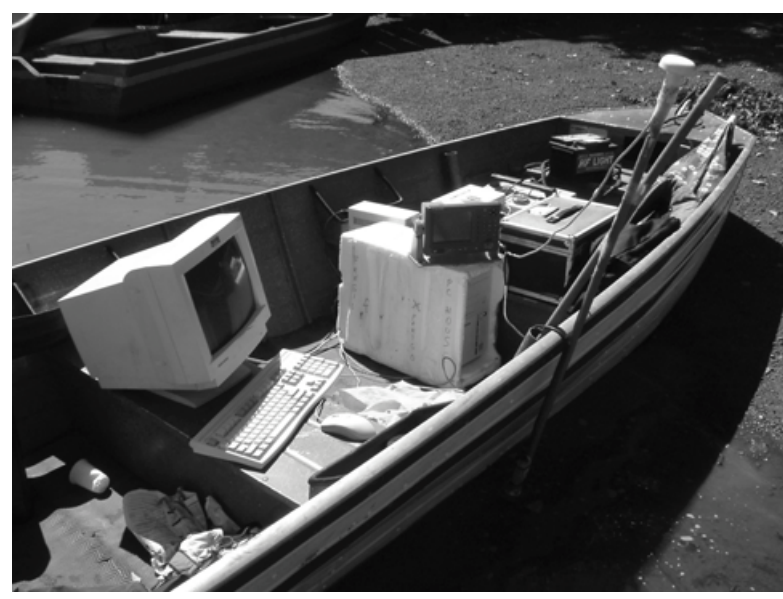

Figura 3. A) Ecossonda modelo Furuno GP-1650F, B)Sistema de Posicionamento Global (GPS), acoplados a um computador utilizado na realização do levantamento batimétrico.

A escala utilizada no levantamento batimétrico foi de 1:100.000. Adotou-se o distanciamento de $1 \mathrm{~cm}$ no mapa entre os pontos levantados, conforme a proposta da Diretoria de Hidrografia e Navegação (DHN), descrita em Carvalho (1994; 2000), devido à não disponibilidade das cartas topográficas na escala 1:10.000, no período do primeiro trabalho de campo. A malha de perfilagem ecobatimétrica (Fig. 4) foi constituída de 53 linhas navegadas no sentido N-S, espaçadas aproximadamente de $1000 \mathrm{~m}$. No sentido E-W foram navegadas duas linhas com espaço aproximado de $1000 \mathrm{~m}$ entre elas, em uma distância de 3 km.

Para calcular a taxa de sedimentação no reservatório, fez-se uso das cotas altimétricas das cartas topográficas na escala 1:10.000 da época da construção do reservatório e das informações batimétricas obtidas. Isso permitiu a elaboração dos mapas de isóbatas, bem como a confecção de perfis batimétricos.

O cálculo do volume do material sedimentado foi realizado pelo método da planimetria das curvas 
Avaliação do estado de assoreamento do reservatório de Cachoeira Dourada (GO/MG) João Batista Pereira Cabral, Luiz Alberto Fernandes, Iraci Scopel, Valter Antonio Becegato, Alberto Pio Fiori

batimétricas, descrita em Carvalho (1994) e com a SOFTWARE, 1999), descrito em Vilhena et al. (2003). utilização do programa Surfer 8 (GOLDEN

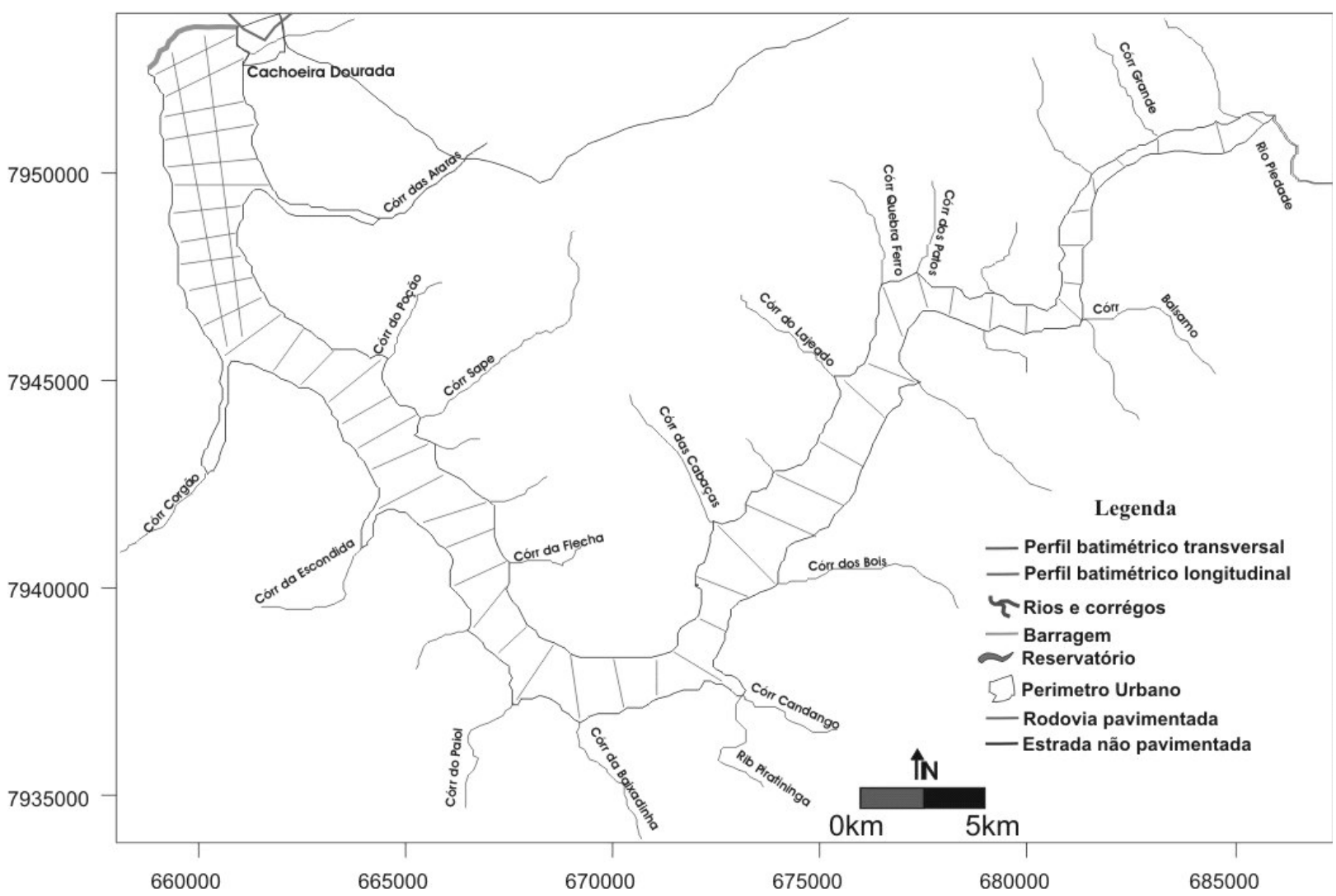

Figura 4. Linhas de perfilagem ecobatimétrica do levantamento do processo de assoreamento do reservatório de Cachoeira Dourada.

\section{Resultados e Discussão}

\subsection{Análise do processo de assoreamento e previsão de vida útil do reservatório}

Os parâmetros granulométricos da porção superficial dos depósitos de fundo, obtidas no primeiro e segundo levantamento a campo são apresentados nas Tab. 1 e 2.
De modo geral, os dados obtidos (Tab. 1 e 2) indicam que os depósitos de assoreamento do reservatório apresentam heterogeneidade granulométrica e podem ser agrupados em dois tipos principais: pelíticos (argilosos e siltosos) e arenosos. 
Avaliação do estado de assoreamento do reservatório de Cachoeira Dourada (GO/MG)

João Batista Pereira Cabral, Luiz Alberto Fernandes, Iraci Scopel, Valter Antonio Becegato, Alberto Pio Fiori

Tabela 1: Características das partículas, obtidas nas análises granulométricas das amostras do primeiro levantamento de campo relativo ao período úmido (6/2/2003 e 7/2/2003).

\begin{tabular}{|c|c|c|c|c|c|c|c|c|}
\hline Amostra & $\begin{array}{l}\text { Diâmetro } \\
\text { médio }(\varnothing)\end{array}$ & $\begin{array}{c}\text { Desvio } \\
\text { padrão (Ø) }\end{array}$ & Assimetria & Curtose & $\begin{array}{c}\text { Cascalho } \\
(\%)\end{array}$ & $\begin{array}{c}\text { Areia } \\
(\%)\end{array}$ & $\begin{array}{l}\text { Silte } \\
(\%)\end{array}$ & $\begin{array}{c}\text { Argila } \\
(\%)\end{array}$ \\
\hline $1^{a}$ & 05.02 & 01.72 & 00.48 & 01.93 & 00.00 & 29.00 & 58.43 & 12.57 \\
\hline 1B & 06.62 & 02.32 & -00.47 & 01.01 & 00.00 & 15.00 & 47.63 & 37.37 \\
\hline $1 \mathrm{C}$ & 05.82 & 01.93 & 00.33 & 00.60 & 00.70 & 19.01 & 56.36 & 23.91 \\
\hline $1 \mathrm{D}$ & 07.58 & 01.19 & -00.46 & 00.78 & 00.00 & 01.60 & 49.01 & 49.38 \\
\hline $1 \mathrm{E}$ & 05.77 & 02.25 & 00.01 & 00.66 & 00.00 & 31.81 & 44.79 & 23.40 \\
\hline 2 & 05.75 & 02.73 & -00.42 & 00.67 & 00.00 & 25.87 & 38.16 & 35.97 \\
\hline $3^{a}$ & 07.62 & 01.44 & -00.57 & 01.13 & 00.00 & 09.45 & 39.65 & 50.90 \\
\hline $3 \mathrm{~B}$ & 06.14 & 02.13 & -00.15 & 00.52 & 00.00 & 29.95 & 35.53 & 34.52 \\
\hline $3 \mathrm{C}$ & 02.09 & 00.61 & 00.41 & 01.09 & 00.00 & 96.45 & 01.66 & 01.88 \\
\hline $3 \mathrm{D}$ & 06.04 & 02.17 & -00.12 & 00.54 & 00.00 & 33.72 & 35.32 & 30.96 \\
\hline $4 \mathrm{~A}$ & 02.95 & 00.42 & 00.40 & 01.07 & 00.00 & 96.36 & 01.48 & 02.15 \\
\hline $4 \mathrm{~B}$ & 07.66 & 01.36 & -00.57 & 01.22 & 00.00 & 05.20 & 40.92 & 53.88 \\
\hline 5 & 02.30 & 01.28 & 00.44 & 03.30 & 00.00 & 90.45 & 04.32 & 05.22 \\
\hline 6 & 03.40 & 01.10 & 00.45 & 03.30 & 00.00 & 85.57 & 08.32 & 06.09 \\
\hline 7 & 06.84 & 01.74 & -00.32 & 00.71 & 00.00 & 07.48 & 53.25 & 39.26 \\
\hline $8 \mathrm{~A}$ & 04.03 & 02.07 & 00.82 & 05.52 & 00.00 & 77.31 & 09.23 & 13.46 \\
\hline $8 \mathrm{~B}$ & 04.74 & 02.20 & 00.49 & 00.56 & 00.01 & 52.61 & 38.85 & 08.52 \\
\hline $8 \mathrm{C}$ & 07.47 & 01.26 & -00.43 & 00.78 & 00.00 & 01.03 & 51.85 & 47.11 \\
\hline $9 \mathrm{~A}$ & 02.28 & 01.02 & 00.37 & 02.22 & 00.00 & 92.95 & 04.53 & 02.51 \\
\hline 9B & 04.36 & 02.56 & 00.74 & 00.60 & 00.60 & 67.91 & 11.89 & 19.60 \\
\hline $10 \mathrm{~A}$ & 02.29 & 01.24 & 00.49 & 04.13 & 00.00 & 90.66 & 04.49 & 04.84 \\
\hline $10 \mathrm{~B}$ & 05.71 & 01.94 & 00.51 & 00.56 & 00.00 & 18.81 & 54.09 & 27.11 \\
\hline 11 & 06.54 & 02.43 & -00.62 & 01.29 & 00.00 & 16.93 & 41.26 & 41.80 \\
\hline 12 & 02.12 & 00.55 & 00.34 & 01.07 & 00.00 & 95.86 & 01.78 & 02.34 \\
\hline $13 \mathrm{~A}$ & 05.03 & 02.15 & 00.60 & 00.71 & 00.20 & 51.29 & 31.78 & 16.73 \\
\hline $13 \mathrm{~B}$ & 03.95 & 03.71 & 00.01 & 00.51 & 00.00 & 51.13 & 18.38 & 30.49 \\
\hline 14 & 01.63 & 00.61 & 00.03 & 01.50 & 00.07 & 97.07 & 01.39 & 01.46 \\
\hline 15 & 01.48 & 00.76 & 00.04 & 01.88 & 00.00 & 95.10 & 04.05 & 00.84 \\
\hline 16 & 06.30 & 02.00 & -00.09 & 00.60 & 00.03 & 17.25 & 46.06 & 36.65 \\
\hline 17 & 05.10 & 02.04 & 00.71 & 00.78 & 00.00 & 55.54 & 27.46 & 17.00 \\
\hline $18 \mathrm{~A}$ & 00.96 & 00.84 & 00.12 & 01.01 & 00.02 & 96.37 & 01.67 & 01.92 \\
\hline $18 \mathrm{~B}$ & 00.59 & 00.87 & -00.13 & 01.38 & 08.10 & 90.75 & 01.07 & 00.04 \\
\hline 19 & 02.34 & 00.52 & 00.11 & 01.14 & 00.00 & 95.92 & 02.11 & 01.90 \\
\hline
\end{tabular}


Avaliação do estado de assoreamento do reservatório de Cachoeira Dourada (GO/MG) João Batista Pereira Cabral, Luiz Alberto Fernandes, Iraci Scopel, Valter Antonio Becegato, Alberto Pio Fiori

Tabela 2: Características das partículas, obtidas nas análises granulométricas das amostras do segundo levantamento de campo relativo ao período seco (03 a 04/05/2005).

\begin{tabular}{|c|c|c|c|c|c|c|c|c|}
\hline Amostra & $\begin{array}{l}\text { Diâmetro } \\
\text { médio }(\varnothing)\end{array}$ & $\begin{array}{c}\text { Desvio } \\
\text { padrão (Ø) }\end{array}$ & Assimetria & Curtose & $\begin{array}{c}\text { Cascalho } \\
(\%)\end{array}$ & $\begin{array}{c}\text { Areia } \\
(\%)\end{array}$ & $\begin{array}{l}\text { Silte } \\
(\%)\end{array}$ & $\begin{array}{l}\text { Argila } \\
(\%)\end{array}$ \\
\hline $1^{\mathrm{a}}$ & 07.36 & 01.91 & -00.73 & 01.28 & 00.76 & 13.58 & 24.19 & 61.47 \\
\hline $1 \mathrm{~B}$ & 06.73 & 02.32 & -00.78 & 00.54 & 00.00 & 26.13 & 11.87 & 62.00 \\
\hline $1 \mathrm{C}$ & 07.84 & 01.41 & -00.65 & 01.91 & 02.10 & 05.98 & 24.25 & 67.66 \\
\hline $1 \mathrm{D}$ & 07.38 & 01.85 & -00.73 & 01.23 & 00.00 & 12.17 & 24.73 & 63.10 \\
\hline $2^{\mathrm{a}}$ & 07.20 & 02.50 & -00.75 & 02.01 & 08.62 & 04.33 & 32.73 & 54.32 \\
\hline $2 \mathrm{~B}$ & 07.16 & 01.72 & -00.57 & 00.71 & 00.02 & 07.97 & 43.42 & 48.58 \\
\hline $2 \mathrm{C}$ & 06.81 & 02.21 & -00.73 & 00.64 & 00.00 & 22.54 & 25.02 & 52.44 \\
\hline $3^{a}$ & 06.44 & 02.54 & -00.62 & 00.73 & 00.00 & 23.53 & 30.97 & 45.50 \\
\hline $3 \mathrm{~B}$ & 07.13 & 01.76 & -00.65 & 00.64 & 01.14 & 04.15 & 43.37 & 51.33 \\
\hline $4^{a}$ & 04.90 & 02.94 & 00.32 & 00.86 & 09.28 & 49.30 & 17.02 & 24.40 \\
\hline $4 \mathrm{~B}$ & 07.61 & 01.52 & -00.69 & 01.46 & 00.47 & 06.15 & 27.70 & 65.67 \\
\hline $5^{a}$ & 07.48 & 01.59 & -00.68 & 00.99 & 00.00 & 06.85 & 31.40 & 61.74 \\
\hline $5 \mathrm{~B}$ & 07.44 & 02.30 & -00.71 & 01.90 & 06.40 & 05.06 & 35.21 & 53.32 \\
\hline 6 & 07.15 & 01.62 & -00.53 & 00.69 & 00.00 & 02.88 & 51.48 & 45.63 \\
\hline $7^{\mathrm{a}}$ & 06.14 & 02.46 & -00.30 & 00.69 & 00.00 & 25.06 & 34.46 & 40.49 \\
\hline $7 B$ & 05.88 & 02.39 & -00.14 & 00.59 & 00.00 & 33.30 & 33.14 & 33.56 \\
\hline $8^{a}$ & 06.85 & 02.37 & -00.78 & 01.00 & 00.17 & 18.05 & 23.28 & 58.50 \\
\hline $8 \mathrm{~B}$ & 02.48 & 00.49 & -00.02 & 01.24 & 02.29 & 95.42 & 01.43 & 00.85 \\
\hline $9^{a}$ & 04.00 & 03.01 & 00.42 & 01.40 & 06.30 & 67.14 & 11.35 & 15.20 \\
\hline $9 \mathrm{~B}$ & 05.99 & 02.25 & -00.02 & 00.61 & 00.00 & 28.69 & 36.97 & 34.34 \\
\hline $10^{\mathrm{a}}$ & 06.19 & 00.44 & 00.03 & 00.98 & 01.74 & 97.88 & 00.37 & 00.00 \\
\hline 10B & 02.19 & 02.32 & -00.22 & 00.67 & 00.44 & 22.89 & 36.96 & 39.70 \\
\hline $11^{\mathrm{a}}$ & 04.58 & 02.52 & 00.51 & 02.89 & 01.59 & 75.16 & 07.55 & 15.69 \\
\hline 11B & 06.22 & 02.25 & -00.26 & 00.58 & 01.37 & 27.46 & 31.71 & 39.45 \\
\hline $12^{\mathrm{a}}$ & 02.55 & 00.84 & -00.49 & 03.28 & 05.53 & 91.99 & 02.13 & 00.33 \\
\hline $12 \mathrm{~B}$ & 04.06 & 02.74 & 00.50 & 01.25 & 03.06 & 67.45 & 15.44 & 14.04 \\
\hline 13 & 05.29 & 02.40 & 00.31 & 00.58 & 00.10 & 43.18 & 29.86 & 26.85 \\
\hline $14^{\mathrm{a}}$ & 04.58 & 02.34 & 00.63 & 01.82 & 00.00 & 74.62 & 09.70 & 15.67 \\
\hline 14B & 02.52 & 00.70 & 00.02 & 00.94 & 00.07 & 97.36 & 02.47 & 00.09 \\
\hline $15 \mathrm{~B}$ & 04.77 & 02.39 & 00.56 & 01.00 & 00.51 & 65.39 & 17.20 & 16.88 \\
\hline $15^{\mathrm{a}}$ & 02.01 & 00.49 & 00.16 & 01.04 & 00.00 & 98.24 & 01.14 & 00.62 \\
\hline 16 & 06.32 & 01.72 & 00.26 & 00.57 & 00.00 & 02.55 & 63.85 & 33.59 \\
\hline 17 & 01.90 & 00.37 & 00.24 & 01.12 & 00.00 & 100.00 & 00.00 & 00.00 \\
\hline 18 & 04.95 & 02.37 & 00.51 & 00.70 & 00.32 & 51.10 & 27.75 & 20.83 \\
\hline 19 & -00.75 & -00.45 & -00.20 & 00.73 & 100 & 00.00 & 00.00 & 00.00 \\
\hline 20 & 01.53 & 00.49 & -00.16 & 01.15 & 00.09 & 99.91 & 00.00 & 00.00 \\
\hline 21 & 01.91 & 00.59 & 00.21 & 01.22 & 00.00 & 97.84 & 01.23 & 00.92 \\
\hline
\end{tabular}


Os pelíticos ocorrem entre a barragem e o córrego do Corgão (Fig. 4 e 5). O material de granulação mais grossa (areia média e grossa) é depositado principalmente na desembocadura do rio Piedade. Em geral, predomina material pobremente selecionado e muito pobremente selecionado em ambos os períodos, apresentando distribuições assimetria positiva e negativa respectivamente.

Ponçano et al. (1976) destacam a importância do estudo do diâmetro médio como medida de tendência central mais importante na caracterização dos sedimentos, pois, além de caracterizar a distribuição granulométrica da área de estudo, fornece uma primeira indicação global a respeito das energias envolvidas nos processos deposicionais.

A análise da distribuição dos sedimentos no fundo do lago revelou nítida diferenciação espacial do diâmetro médio (Fig. 5 e 6). Na Fig. 5, nota-se que, no período úmido (maior intensidade de chuva), a variação da distribuição dos sedimentos arenosos ocorre preferencialmente do rio Piedade (sedimentos mais grossos) até as proximidades do córrego do Corgão, onde passam a predominar os sedimentos mais finos.

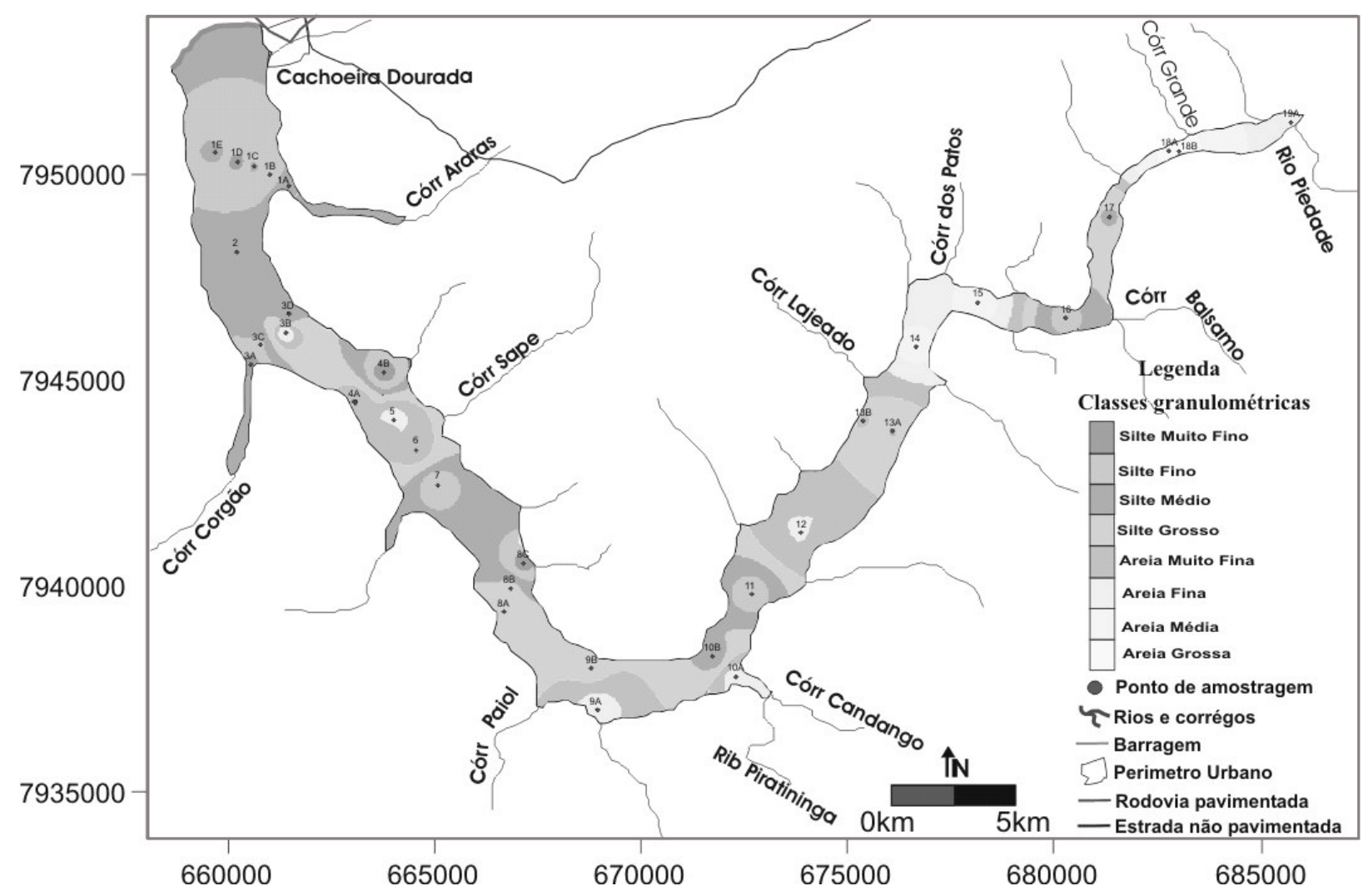

Figura 5. Distribuição dos valores da média granulométrica dos sedimentos de fundo, referente ao período úmido.

No período seco (menor intensidade de chuva) (Fig. 6), esta variação se dá preferencialmente do rio Piedade ao córrego do Paiol. Tal distribuição parece estar relacionada à localização das áreas-fonte arenosas, ativas - presentes na bacia do reservatório e aos aportes fluviais a que estão sujeitas.
Na primeira amostragem a campo, o diâmetro médio dos sedimentos variou entre silte muito fino e areia grossa ( $\varnothing$ de 0,59 e 7,6 respectivamente) e na segunda amostragem a campo, entre silte muito fino e areia muito grossa ( $\varnothing$ de $-0,75$ a 7,8 respectivamente). 
Avaliação do estado de assoreamento do reservatório de Cachoeira Dourada (GO/MG) João Batista Pereira Cabral, Luiz Alberto Fernandes, Iraci Scopel, Valter Antonio Becegato, Alberto Pio Fiori

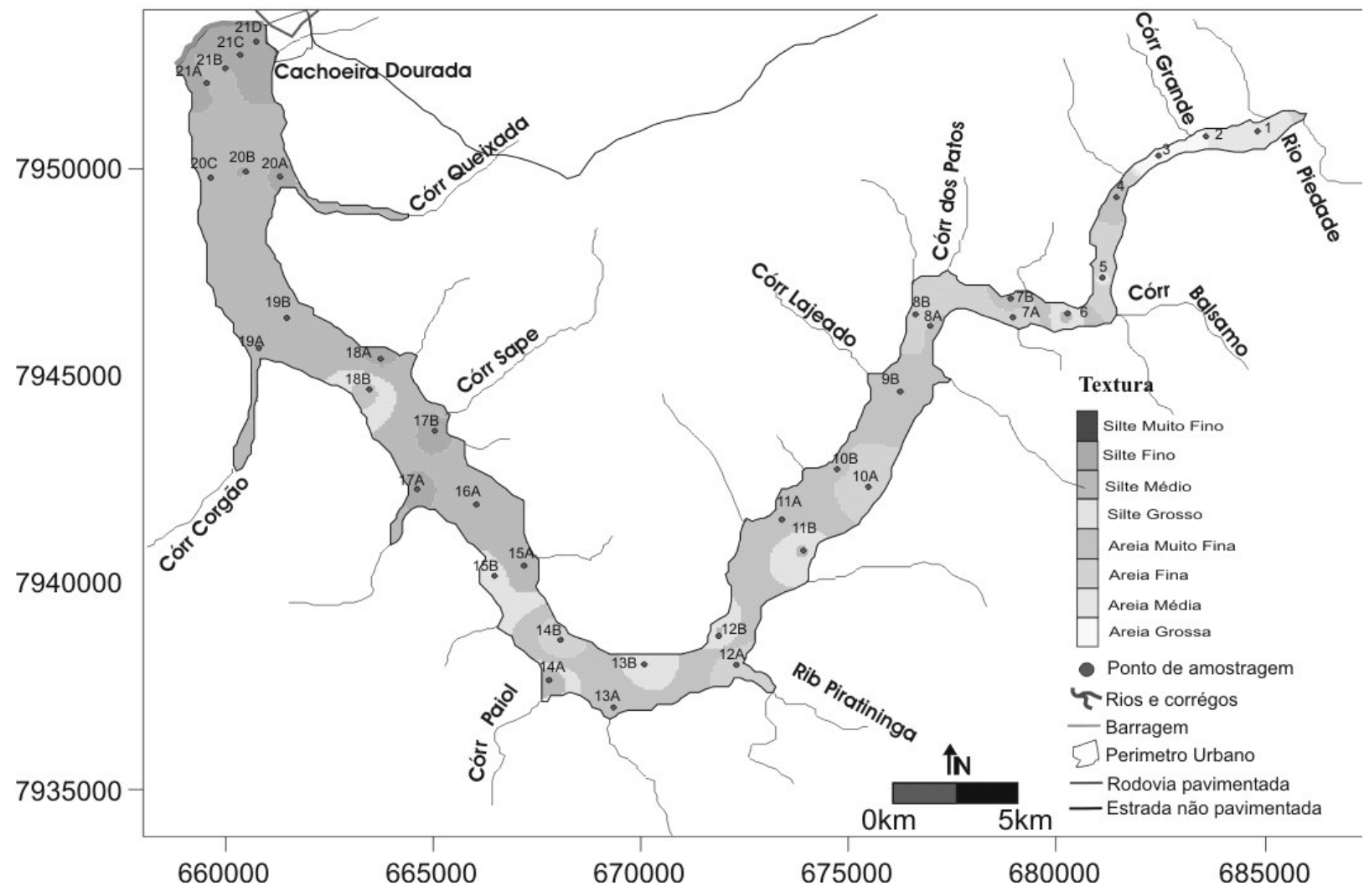

Figura 6. Distribuição dos valores da média granulométrica dos sedimentos de fundo, referente ao período seco.

O diâmetro médio $\left(\mathrm{D}_{50}\right)$ pode estar diretamente associado à energia dos processos atuantes nos diferentes ambientes deposicionais. No período úmido ocorreu heterogeneidade em relação ao diâmetro médio dos sedimentos do reservatório, misturando-se os silto-argilosos com os arenosos. Os materiais arenosos, embora possam ser transportados em suspensão, dependendo da energia e do diâmetro das areias, são predominantemente transportados por arrasto no período de maior precipitação na bacia, sendo seu ponto máximo de transporte próximo à área de influência do córrego do Corgão (Fig. 6).

Esta análise dos sedimentos, em relação ao diâmetro médio, demonstra que a redução da velocidade das correntes, em decorrência do estabelecimento do barramento, favoreceu a deposição gradual de sedimentos ao longo do reservatório e diminuiu gradativamente sua capacidade de armazenamento. Além disso, os sedimentos que não são retidos no reservatório, passam pelo vertedouro e condutos principais das turbinas, podendo causar abrasão nas estruturas, comportas, tubulações e turbinas.

Os mapas de distribuição de valores dos diâmetros médios (Fig. 5 e 6) mostram uma distribuição gradativa dos materiais mais grossos para os mais finos de forma ordenada a partir da cabeceira e entradas laterais do reservatório em direção ao centro.

Em geral, é possível destacar que entre a barragem e o córrego do Paiol ocorre o predomínio de material silte argiloso. As areias finas a muito finas, oriundas de desagregação de arenitos da Formação Vale do Rio do Peixe, são carreadas pelo córrego do Candango e ribeirão Piratininga podendo ser transportadas até a área de influência do córrego do Corgão. O material de granulação mais grossa é depositado, principalmente, nas desembocaduras do ribeirão Piratininga e do rio Piedade. 
Os valores de diâmetro médio das amostras denotam com clareza as modificações no sentido do transporte de montante para jusante em ambos os períodos. As areias médias a grossas são depositadas entre o rio Piedade e córrego do Bálsamo, prevalecendo ações mais efetivas de processos de energia mais acentuada e às modificações da topografia de fundo pelo trabalho das dragas. Entre os córregos do Paiol e do Candango, localiza-se a principal área de aporte de areia fina a muito fina.

Quanto ao processo de deposição de sedimentos, Coelho (1993) tem uma explicação distinta. No reservatório de Americana, este autor relacionou tal processo à variação do nível do reservatório, pelo modo de operação e, também, aos vales submersos, que impedem, em certos setores, a progressão da corrente de densidade e às diferentes litologias existentes na bacia.

Para Suguio (1973), o grau de seleção pode estar associado ao mecanismo de transporte das partículas no ambiente fluvial. Esse autor destaca que o grau de seleção dos sedimentos aumenta com a distância transportada, tendo como consequência um decréscimo das classes granulométricas.

No reservatório de Cachoeira Dourada, os sedimentos de fundo apresentaram grau de seleção entre muito pobremente selecionado a bem selecionado no período úmido (Ø entre 0.42 e 3.71 ) e muito pobremente selecionado e muito bem selecionado no período seco (Ø entre 0.45 e 3.01 ), representados nas Fig. 7 e 8 . Tal característica sugere um ambiente favorável à mistura de fontes e/ou à inexistência de um mecanismo de transporte único.

De forma geral, verificou-se que os sedimentos classificados como bem selecionados ocorreram para as areias finas e médias, localizadas nos pontos de amostragem que recebem sedimentos das áreas de ocorrência das formações Marília e Vale do Rio do Peixe. Já o material muito pobremente selecionado corresponde ao silte fino a grosso e pode estar relacionado à alteração dos materiais oriundos da Formação Serra Geral, que predomina na área de entorno do reservatório.

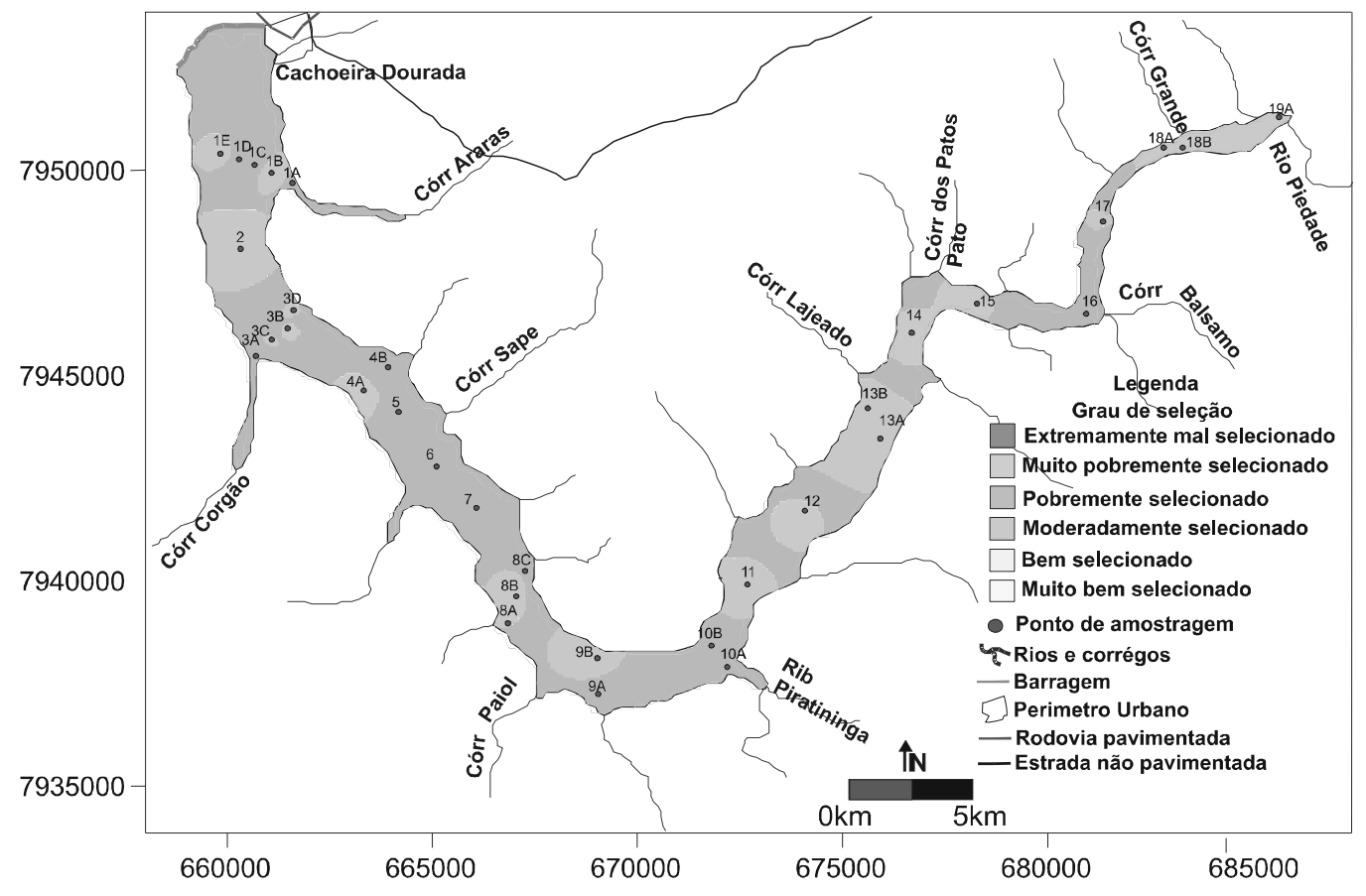

Figura 7. Distribuição dos valores do grau de seleção dos sedimentos de fundo, referente à amostragem no período úmido. 
Avaliação do estado de assoreamento do reservatório de Cachoeira Dourada (GO/MG) João Batista Pereira Cabral, Luiz Alberto Fernandes, Iraci Scopel, Valter Antonio Becegato, Alberto Pio Fiori

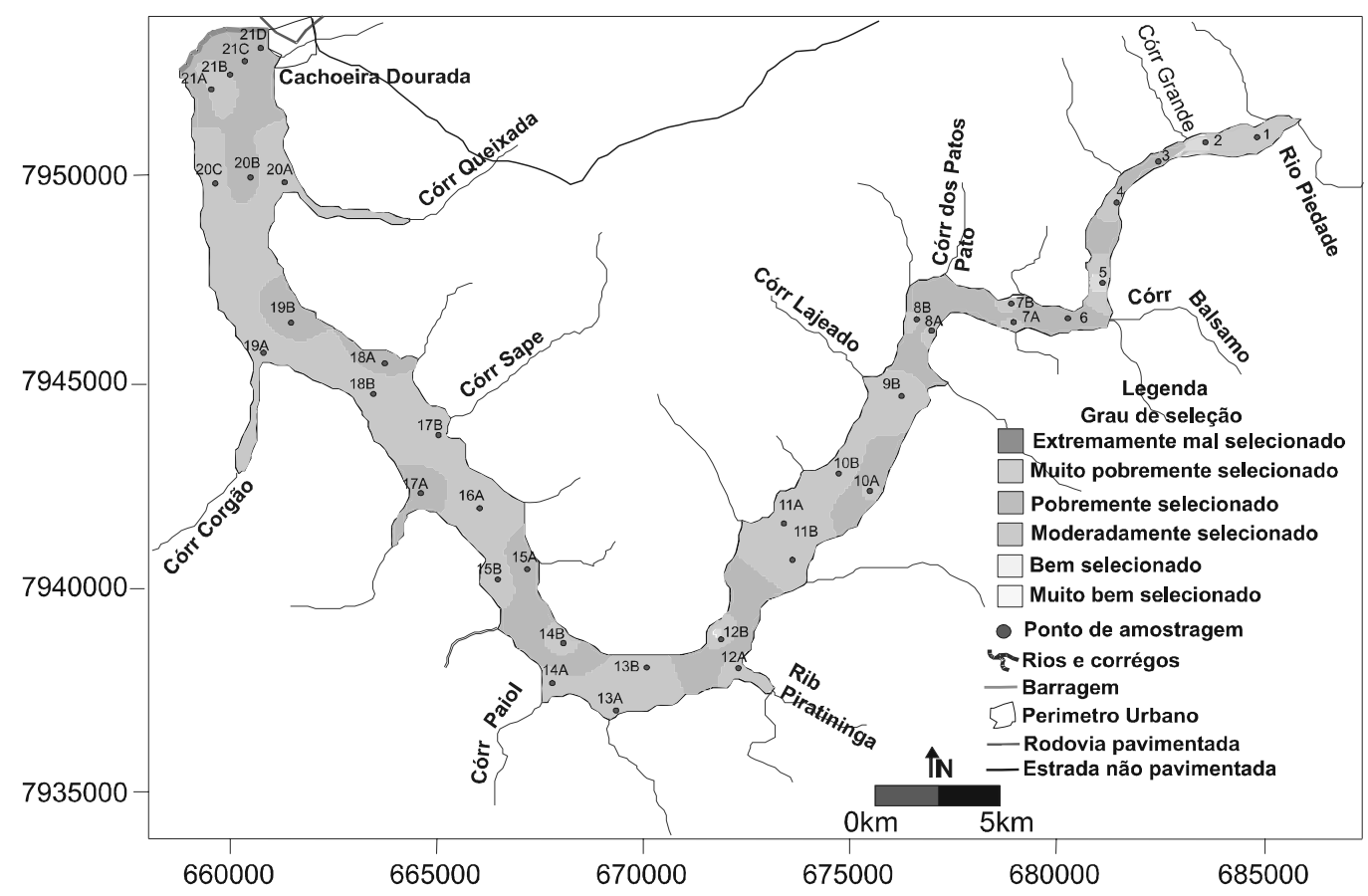

Figura 8. Distribuição dos valores do grau de seleção dos sedimentos de fundo, referente à amostragem no período seco.

$\mathrm{Na}$ avaliação da distribuição espacial do grau de seleção no reservatório (Fig. 7 e 8), verifica-se que, tanto no período úmido quanto no seco, os sedimentos de fundo do lago encontram-se mal selecionados, demonstrando que a distância das áreasfonte em relação ao reservatório não é o único fator a ser levado em consideração para que os sedimentos cheguem a atingir melhor grau de seleção (quanto ao arredondamento e esfericidade), cujas explicações podem ser: diminuição da velocidade de escoamento original do rio alterada pelo seu barramento; aumento da seção transversal e suavização do relevo de fundo, face a deposição de sedimentos.

No caso de Cachoeira Dourada, o que explica os tipos de materiais sedimentados ao longo do lago são as diferentes áreas-fonte, as características específicas dos materiais que aportam para o corpo d'água, associadas aos valores médios anuais de erosividade e pluviosidade, à velocidade de escoamento da água, às feições morfológicas do reservatório, fazendo deste ambiente um sistema complexo quanto aos processos de sedimentação.

Outros fatores que devem ser levados em consideração são as características do relevo da bacia e os solos predominantes (Latossolos). $\mathrm{Na}$ área do reservatório de Cachoeira Dourada, predominam vertentes com declividade entre 3 e $15^{\circ}$, com padrão de drenagem dendrítico e relevo suavemente ondulado. Para tais situações, recomenda-se como prática de conservação do solo, o cultivo em nível.

Quanto aos valores de assimetria das curvas granulométricas dos sedimentos de fundo, tais parâmetros são os que mais diferem em relação aos períodos estudados. As Fig. 9 e 10 indicam que há deposição de sedimentos finos em maior proporção no período seco, principalmente no sentindo do córrego do Paiol para o barramento do reservatório. Isso ocorre sempre nas áreas de menor movimentação de correntes de fundo, a qual é proporcionada pela menor velocidade de escoamento da água e pela forma do fundo suavemente plano. Deve-se ainda à deposição de sedimentos e à maior seção transversal.

No conjunto das amostras referentes aos dois períodos estudados, a assimetria variou de muito negativa a muito positiva, cujos valores encontrados são $-0.62 \varnothing$ e $0.82 \varnothing$ respectivamente. Este é um 
parâmetro que permite inferir sobre o grau de mistura de diferentes populações em um ambiente (SUGUIO, 1973).

Os valores de assimetria muito positiva e positiva ocorrem nos locais de deposição de silte médio a areia grossa, em áreas de maior velocidade de escoamento da água e maior energia de transporte, bem como em áreas que apresentam influência do material arenoso, oriundo da alteração de arenitos e rochas do Complexo Granítico Gnaíssico.
Os coeficientes de assimetria muito negativa e negativa correspondem à locais de deposição de silte muito fino a silte fino, em áreas de menor velocidade de escoamento da água e maior incidência de materiais, possivelmente, originados da Formação Serra Geral.

As curvas granulométricas, aproximadamente simétricas, correspondem principalmente às areias finas e médias, com o predomínio das frações acima de $95 \%$ em relação aos siltes e argilas.

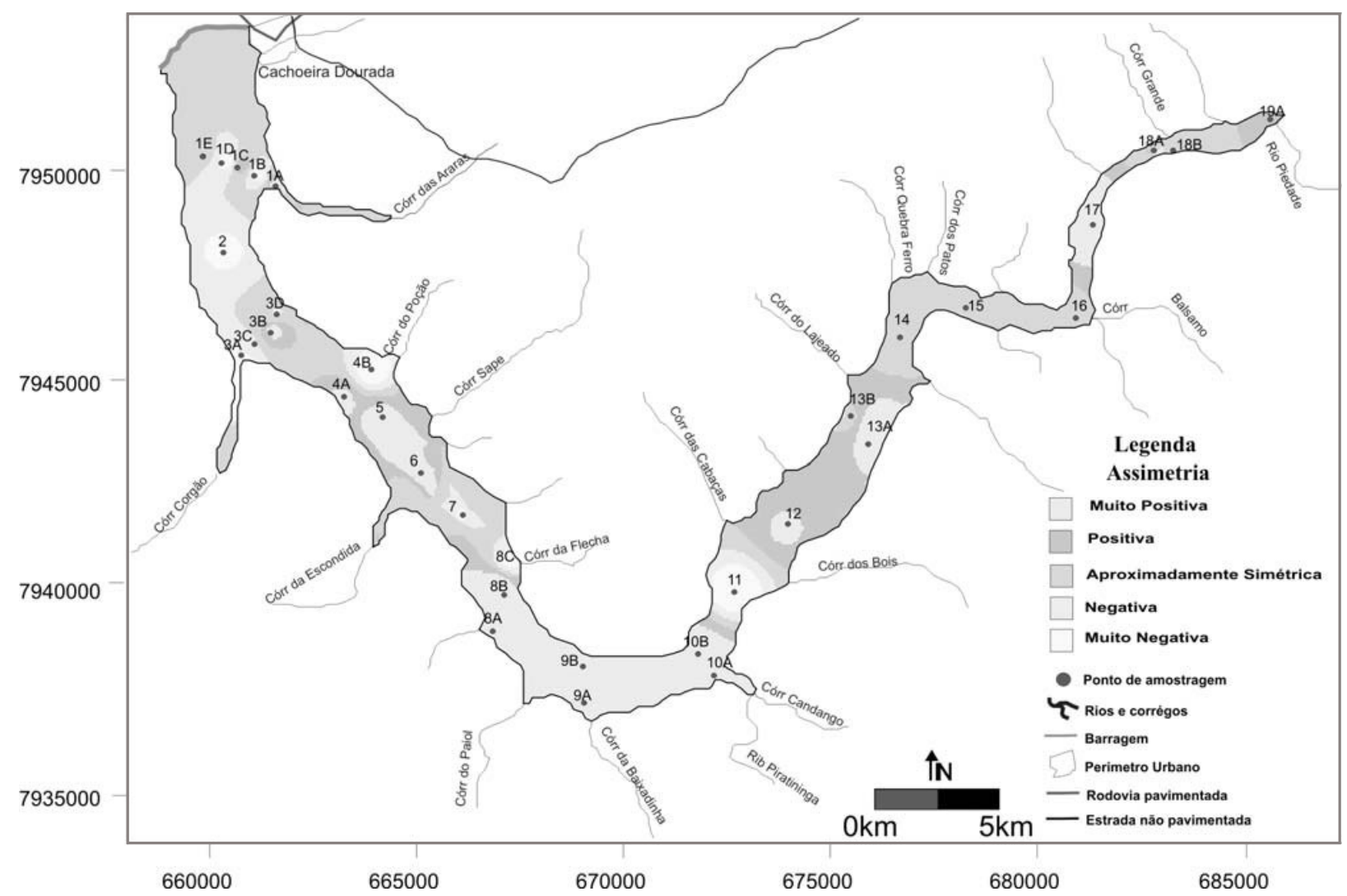

Figura 9. Distribuição dos valores do grau de assimetria, referente à amostragem no período úmido. 
Avaliação do estado de assoreamento do reservatório de Cachoeira Dourada (GO/MG) João Batista Pereira Cabral, Luiz Alberto Fernandes, Iraci Scopel, Valter Antonio Becegato, Alberto Pio Fiori

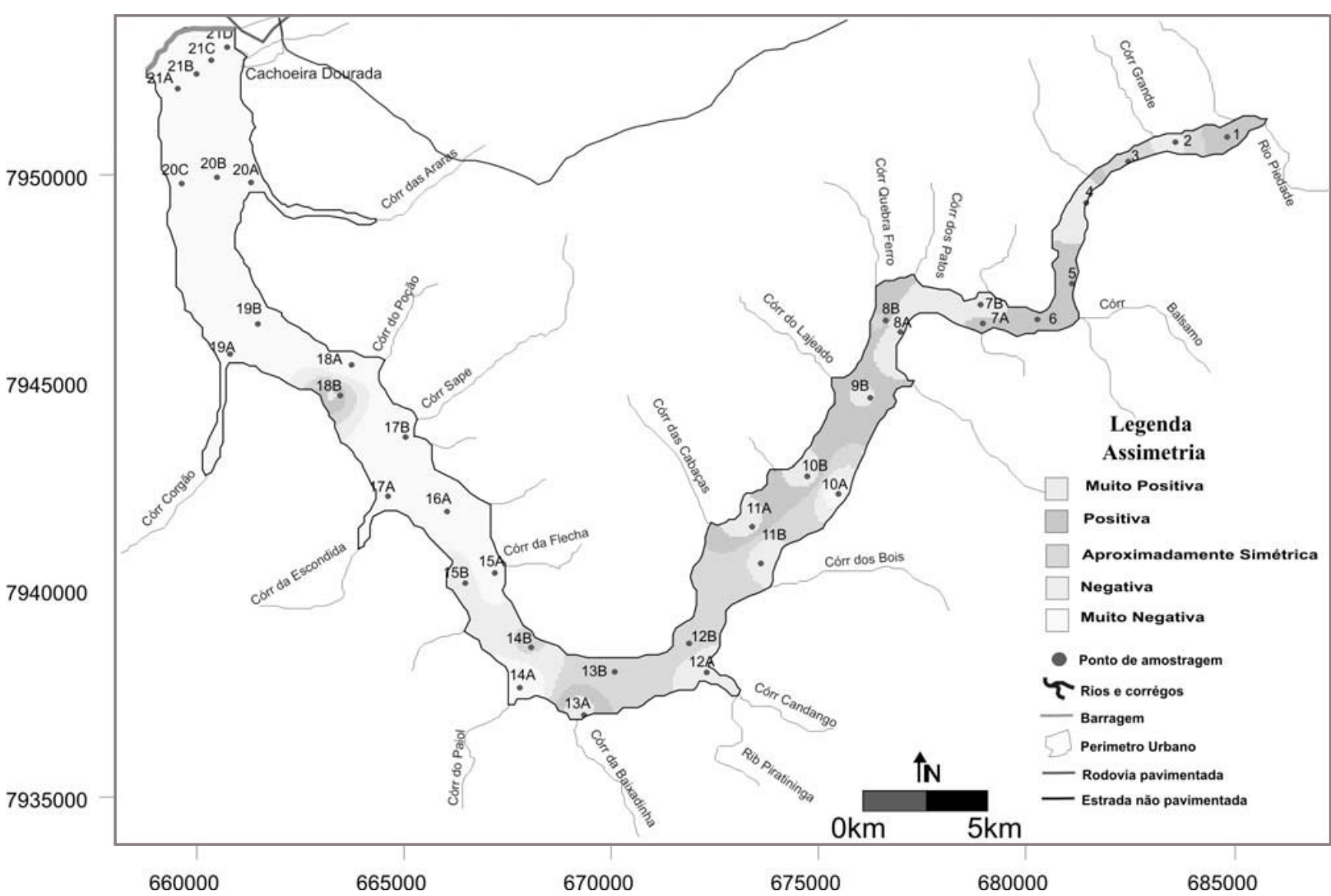

Figura 10. Distribuição dos valores do grau de assimetria, referente à amostragem no período seco.

Quanto à avaliação estatística dos dados amostrados, é possível dizer que as variações do diâmetro médio podem estar relacionadas às variações ambientais e antrópicas que ocorrem na bacia e à alguns pontos de amostragem diferentes, utilizados nos levantamentos de 2003 e de 2005, estes, provavelmente, prejudicando, em parte, a acurácia da comparação.
Outro fator importante observado a campo, que esta relacionada ao processo de assoreamento, é a retirada da vegetação natural nas margens do reservatório (Fig. 11A e 11B), principalmente entre o barramento e o ribeirão Piratininga. A preservação e a manutenção das matas ciliares tornam-se barreiras ao carreamento para o reservatório, por meio das enxurradas, dos detritos sólidos erodidos e aumentam a resistência dos solos das margens à erosão provocada pelo embate das ondas. 
A)

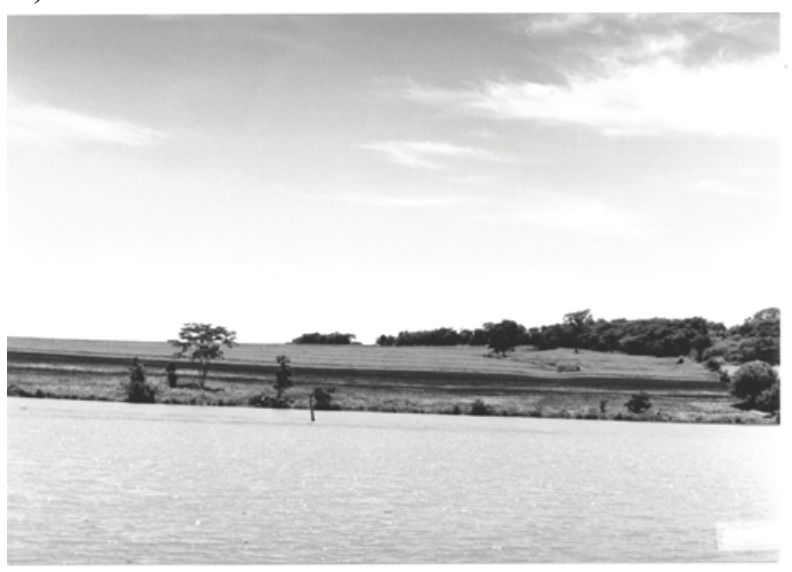

B)

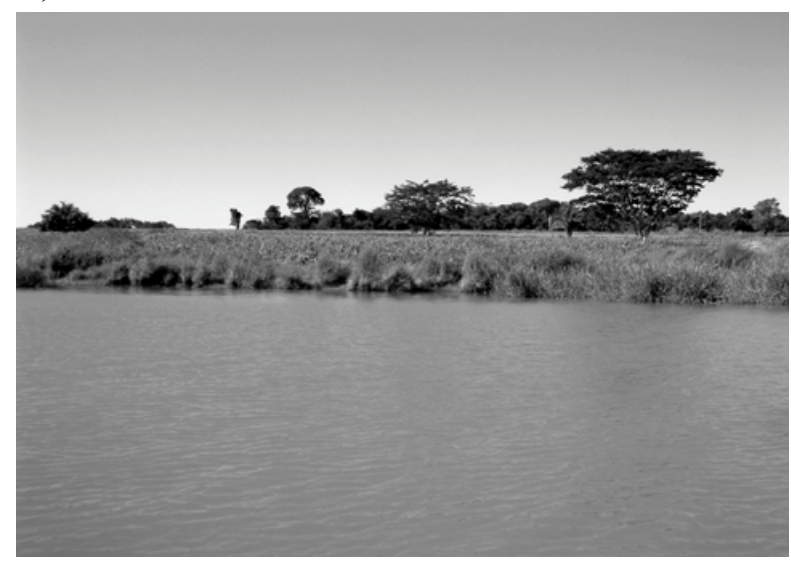

Figura 11A. Exemplo de área ocupada por agricultura na margem esquerda do reservatório; 11B: Área de pastagem nas margens do reservatório, implantada após a retirada das matas ciliares na margem direita do reservatório.

\subsection{Análise conjunta da sedimentação no reservatório (na sua totalidade)}

O reservatório da usina hidrelétrica de Cachoeira Dourada foi projetado para ter um volume de armazenamento de água de $519 \times 10^{6} \mathrm{~m}^{3}$ (Brazilian Committee on Dams - CBDB, 2002) e gerar 658 MW de energia. O volume total de armazenamento, calculado com base nas cartas topográficas (CELG, 1983) foi de $504 \times 10^{6} \mathrm{~m}^{3}$ e $310 \times 10^{6} \mathrm{~m}^{3}$ pelos dados batimétricos (Quadro 1) para os anos de 1959 e 2005 respectivamente. Tais valores são aproximados, em virtude da diferença de datum dos dados obtidos da geração das cartas de 1959 (restituição topográfica, 1:10.000) e do levantamento batimétrico em 2003

Quadro 1: Volume de água armazenada nos períodos estudados.

\begin{tabular}{|c|c|c|c|c|}
\hline Local & Área considerada & $\begin{array}{l}\text { Volume de água } \\
\text { (aproximado) } \\
\text { Inicialx } 10^{6} \mathrm{~m}^{3}\end{array}$ & $\begin{array}{l}\text { Volume de água } \\
\text { (aproximado) } \\
\text { Atual } \times 10^{6} \mathrm{~m}^{3}\end{array}$ & $\begin{array}{c}\text { Volume de } \\
\text { sedimentos depositados } \\
\text { (aproximado) } \times 10^{6} \mathrm{~m}^{3}\end{array}$ \\
\hline Reservatório & barragem ao rio Piedade & 504 & 310 & 194 \\
\hline Setor 1 & $\begin{array}{c}\text { barragem ao } \\
\text { córrego do Corgão }\end{array}$ & 180 & 134 & 46 \\
\hline Setor 2 & $\begin{array}{l}\text { Córrego do Corgão ao } \\
\text { córrego da Flecha }\end{array}$ & 138 & 71 & 67 \\
\hline Setor 3 & $\begin{array}{l}\text { Córrego da Flecha, } 200 \mathrm{~m} \\
\text { após o córrego do Candango }\end{array}$ & 74 & 33 & 41 \\
\hline Setor 4 & $\begin{array}{l}200 \mathrm{~m} \text { após o } \\
\text { córrego do Candango ao } \\
\text { córrego Quebra Ferro }\end{array}$ & 86 & 44 & 42 \\
\hline Setor 5 & $\begin{array}{c}\text { Córrego Quebra } \\
\text { Ferro ao rio Piedade }\end{array}$ & 26 & 28 & 0 \\
\hline
\end{tabular}


Esses dados indicam uma perda aproximada de volume na represa de $38 \%$ ou equivalente à perda de $0,68 \%$ ao ano. Dividindo-se o volume do total depositado $\left(504-310=194 \times 10^{6} \mathrm{~m}^{3}\right)$ pela área superficial do reservatório $\left(74 \mathrm{~km}^{2}\right)$, obter-se-á a profundidade média do depósito, ou seja, ao redor de 2,6m, considerando-se uma distribuição uniforme em toda a área da barragem. Quando se divide esse valor pelo tempo decorrido entre os levantamentos (56 anos), obtém-se uma taxa de sedimentação de $4,68 \mathrm{~cm} /$ ano. Essa taxa é considerada alta quando comparada à de outros reservatórios brasileiros estudados, como aqueles encontrados em Coelho
(1993) e Carvalho (2000).

Entre a barragem e o córrego do Corgão conforme CELG (1994), antes da fase de enchimento existiam planícies de inundação e brejos, principalmente na margem esquerda do rio (Fig. 12), e ilhas no centro do canal; a ilha Grande deve ter se originado de barras laterais longitudinais, e, segundo Bigarella (2003), quando num determinado momento a correnteza torna-se incapaz de transportar sua carga, forma um banco submerso que vai adquirindo expressão à medida que se aproxima da superfície d'água.

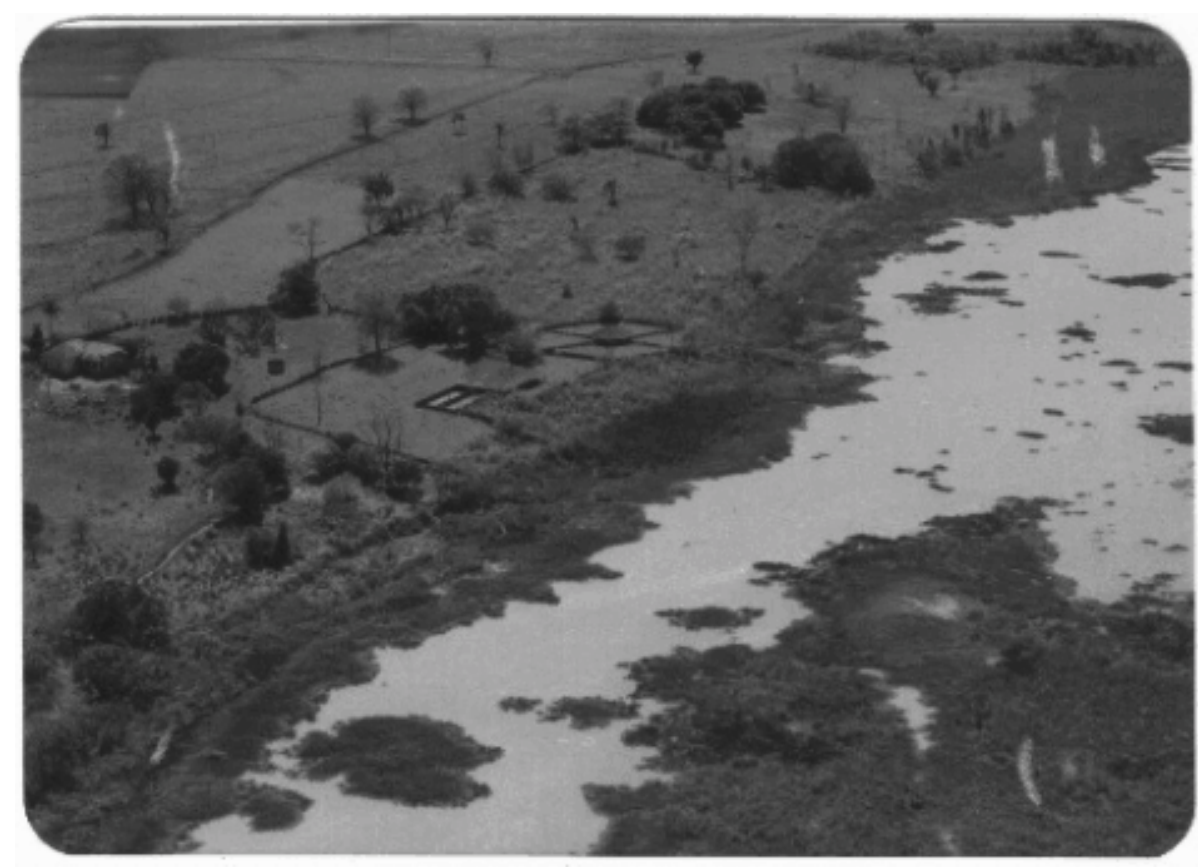

Figura 12. Antiga planície de inundação na margem esquerda do rio Paranaíba, próximo ao barramento, antes da fase de enchimento do lago no ano de 1959 (fonte: Cachoeira Dourada Sociedade Anônima - CDSA, 2003).

Confrontando-se os dados do levantamento batimétrico e a topografia da época da construção do reservatório, constatou-se, a partir do modelo digital do terreno constituído para esse setor, um elevado índice de sedimentação, na porção central do lago e nos antigos canais de contorno da Ilha Grande (Fig. 13 A e B), supondo-se a ocorrência de um afunilamento em direção à barragem e assoreamento, quase por completo, na desembocadura dos córregos das Araras e Corgão (Fig. 13 A e B). 


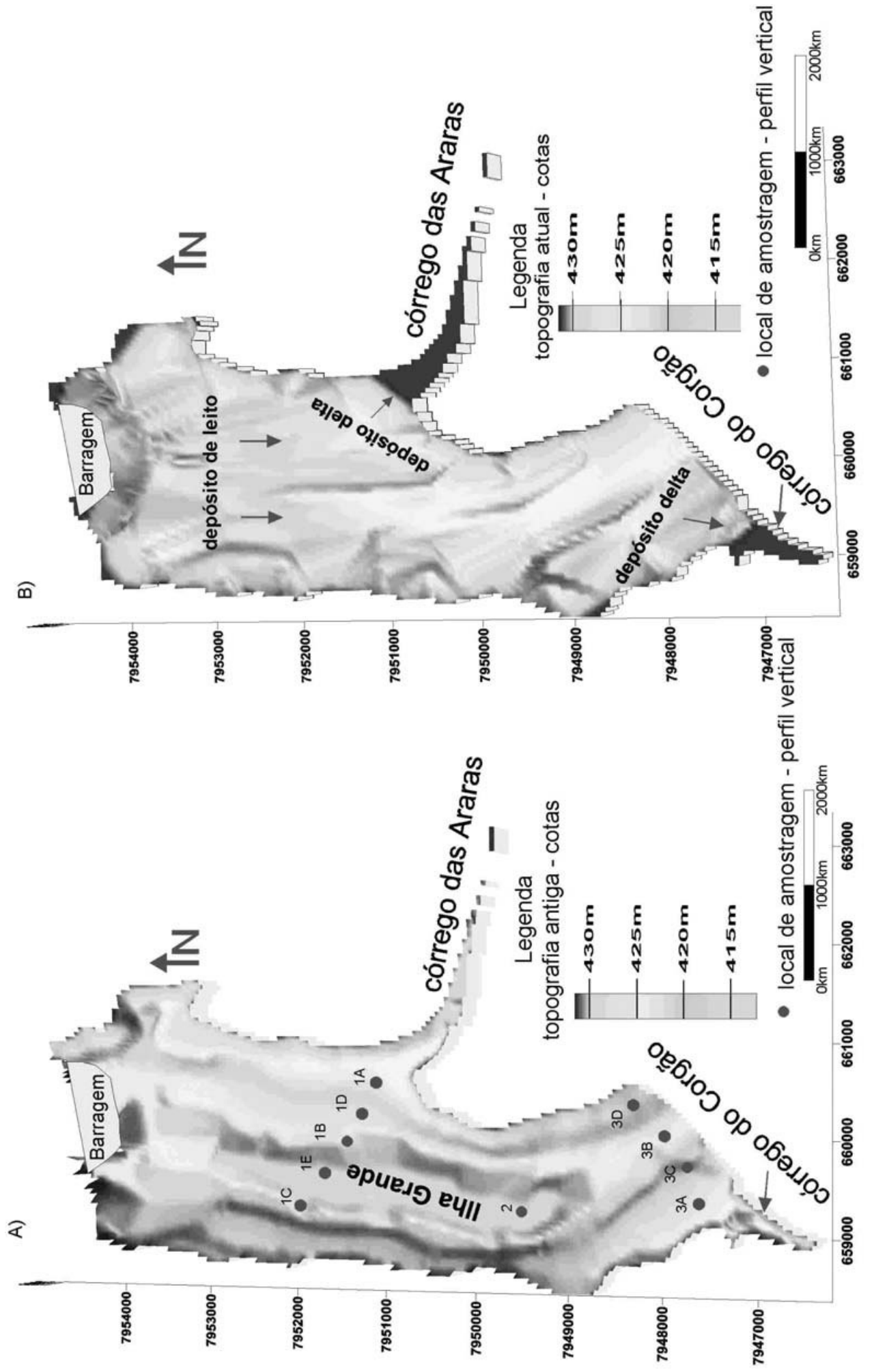

Figura 13. A) Modelo digital do terreno referente ao período anterior a formação do lago, B) período atual, após a fase de enchimento com a deposição de sedimentos. 
O setor com maior índice de assoreamento situa-se entre o córrego do Corgão e da Flecha e Candango, com volume de sedimentos de $67 \times 10^{6} \mathrm{~m}^{3}$, tendo perdido cerca de $48,5 \%$ da sua capacidade de armazenamento quando comparado ao volume inicial. Um valor percentual próximo a este foi verificado por Modesto (1999) na sub-bacia do Ribeirão Apurus no estudo do assoreamento da represa Billings. O autor apontou como causas principais a retirada da cobertura vegetal, a expansão urbana e a criação de clubes de recreação. Nesse setor de Cachoeira Dourada, a bacia hidrográfica é ocupada por práticas agrícolas e pela pecuária de forma predominante.

Entre o córrego da Flecha e Candango, confrontando-se os dados dos perfis topográficos originais e batimétricos atuais, permitiu-se estimar que o material assoreado neste setor correspondesse a $41 \times 10^{6} \mathrm{~m}^{3}$, e a espessura aproximada do depósito sedimentar (considerando-se uma deposição uniforme em toda a área) é de $2,12 \mathrm{~m}$.

A taxa de sedimentação estimada é de $3,7 \mathrm{~cm} /$ ano, considerada alta quando comparada aos outros setores do reservatório anteriormente apresentados. Os modelos digitais do terreno (MDTs) de 1959 e de 2005 (Fig. 14 A e B) mostram tendência geral de assoreamento e o avanço dos depósitos de deltas em direção a jusante, possivelmente em decorrência do avanço dos afluentes (o córrego do Candango e o ribeirão Piratininga), que carreiam para o interior do reservatório sedimentos oriundos da alteração das rochas da Formação Vale do Rio do Peixe.
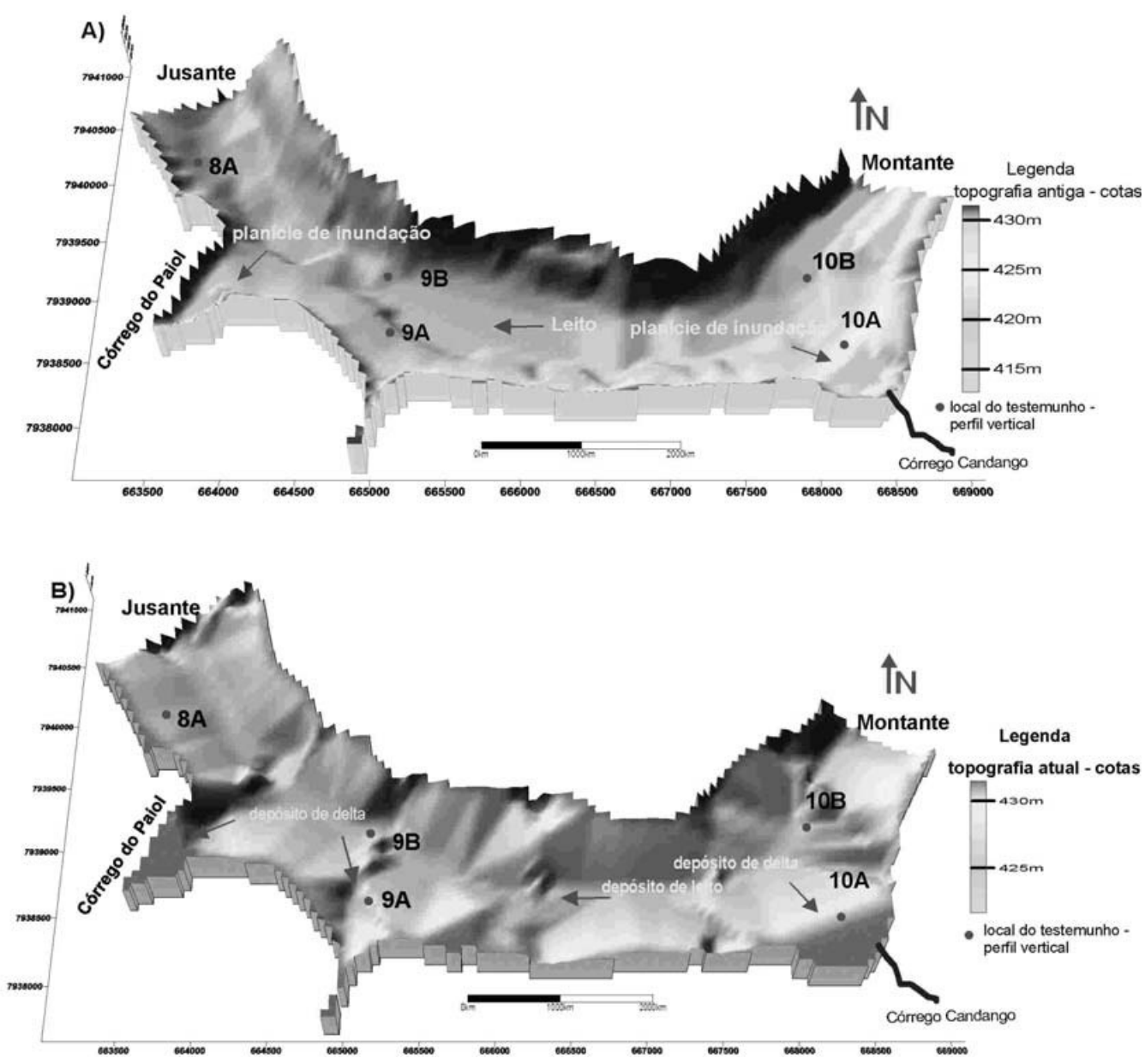

Figura 14: Modelo digital do terreno do setor 3, referente ao período anterior a formação do lago (A) e período atual após a fase de enchimento do lago (B). 
Na Fig. 14 A é possível observar que o antigo leito do rio apresenta-se quase que totalmente assoreado e as antigas áreas de planície dos córregos do Paiol e do Candango, que se encontravam na faixa dos $4 \mathrm{~m}$ de profundidade, caso não ocorresse o processo de sedimentação, hoje se encontram com apenas $1,5 \mathrm{~m}$ de profundidade.
O setor com menor índice de sedimentação corresponde ao trecho entre o córrego Quebra Ferro e o rio Piedade, que teve um aumento do seu volume de água inicial em $2 \times 10^{6} \mathrm{~m}^{3}$. Este aumento de volume pode ser relacionado ao trabalho de exploração de areia com uso de dragas (Fig. 15) que atuam no local e às cartas topográficas desatualizadas.

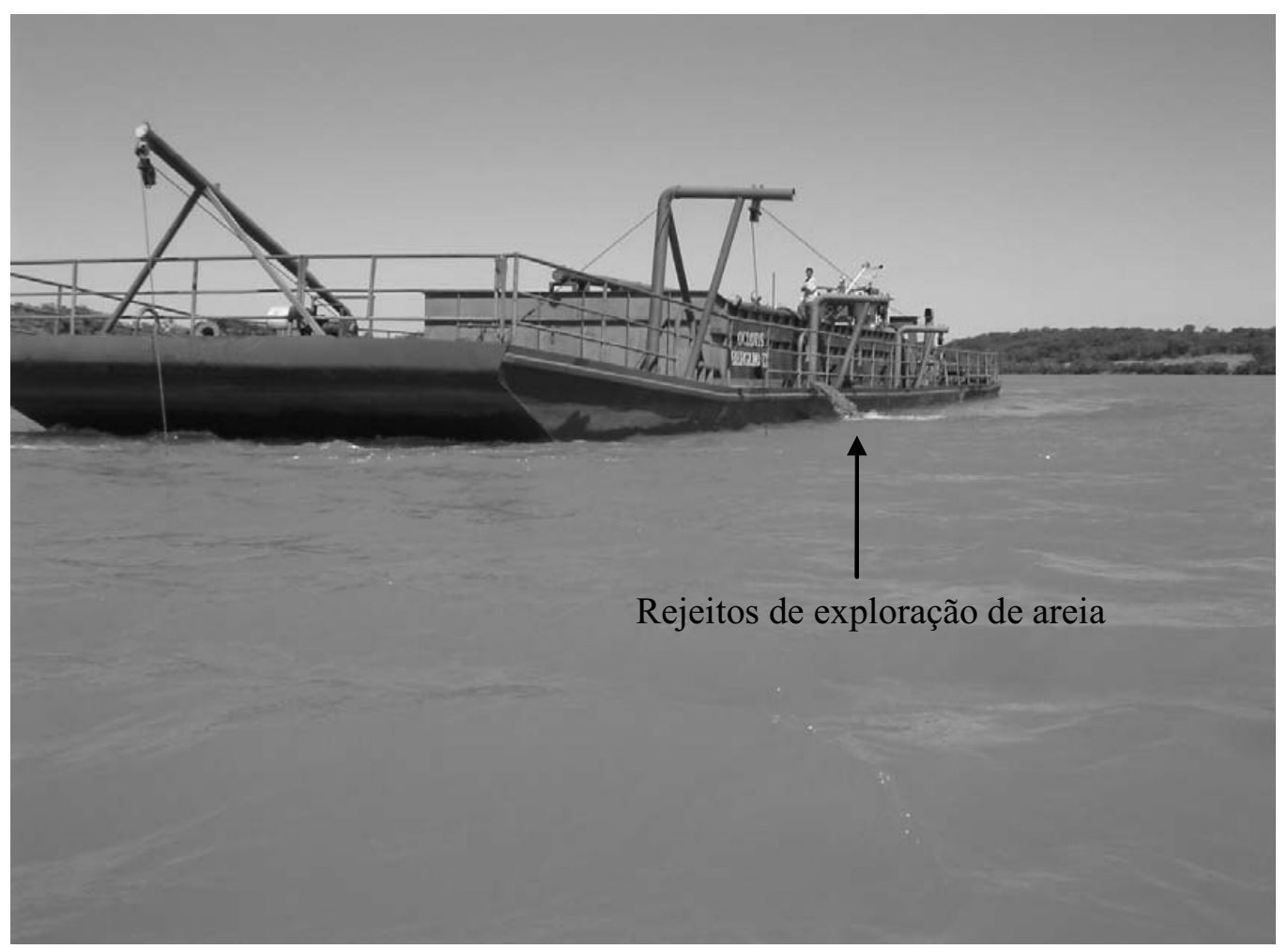

Figura 15. Exemplo de equipamento utilizado para exploração de areia.

Numa análise geral, trabalho semelhante ao desenvolvido em Cachoeira Dourada foi realizado por Vilhena et al. (2003) no reservatório do Funil, localizado no estado do Rio de Janeiro. Após vinte e três anos de operação, comparando-se dados topográficos da época da construção com dados batimétricos de 1992, verificou-se que, o volume total inicial do trecho, estudado em 1969, era de 82,19 milhões de $\mathrm{m}^{3}$; passou a ser de 63,74 milhões de $\mathrm{m}^{3}$ em 1992. Isso corresponde a uma perda da capacidade de armazenamento de 22,93\% em 26 anos, superior, portanto, à perda de capacidade estimada em Cachoeira Dourada.
O fato da taxa de assoreamento de Cachoeira Dourada ser menor do que a do reservatório do Funil pode ser explicado, em parte, em função do complexo de barragens construídas no rio Paranaíba e por Cachoeira Dourada estar situada à jusante dos reservatórios de Itumbiara e Emborcação. Podem ser levados em consideração, ainda, fatores como a retenção de grande parte do material particulado nos reservatórios à montante, o menor tempo de retenção da água no reservatório e o fato da área circundante possuir maior quantidade de solo coberto. 
Avaliação do estado de assoreamento do reservatório de Cachoeira Dourada (GO/MG) João Batista Pereira Cabral, Luiz Alberto Fernandes, Iraci Scopel, Valter Antonio Becegato, Alberto Pio Fiori

\section{Conclusões}

- Comparando as seções topográficas anteriores à formação do lago com as seções de levantamentos batimétricos realizados, estimou-se que o reservatório perdeu cerca de $38,5 \%$ do seu volume inicial, ou seja, o equivalente a uma taxa anual de $0,68 \%$. A espessura do material sedimentado, considerando-se uma deposição uniforme em toda a área, é de 2,62 m, com uma taxa de sedimentação anual de $4,68 \mathrm{~cm} / \mathrm{ano}$. A vida útil estimada para o reservatório no geral é de aproximadamente 145 anos.

- O material coletado na superfície de fundo é constituído principalmente por silte e argila, no setor entre o barramento e o córrego do Corgão. Entre os córregos do Corgão e da Flecha foi verificada a deposição de silte grosso a areia fina. As areias finas a muito finas são carreadas até o córrego do Corgão devido à energia de fluxo existente no local. O material de granulação mais grossa (areia média a grossa) é depositado principalmente na desembocadura do rio Piedade. Entre os córregos do Paiol e do Candango localiza-se a principal área de aporte de material arenoso fino a muito fino e pobremente selecionado. A distância das áreas-fonte em relação ao reservatório não é suficiente para que os sedimentos cheguem a atingir melhor seleção, indicando que os mesmos são poucos retrabalhados.

\section{5 - Referências bibliográficas}

AGÊNCIA GOIANA DE INDÚSTRIA E MINERAÇÃO/COMPANHIA DE RECURSO MINERAIS (AGIM/CPRM). Mapa geológico do estado de Goiás. CD-ROM. 2002.

BACCARO, C.A.D. Estudo dos processos geomorfológicos de escoamento pluvial em área de Cerrado - Uberlândia - MG, 1990, 164 f. Tese (Doutorado em Geografia. Área de concentração Geografia Física). FFLCH/USP, São Paulo, 1990.
BIGARELLA, J. J. Estrutura e origem das paisagens tropicais e subtropicais. Vol 3. Florianópolis: Editora da UFSC. 1346p. 2003.

BRAZILIAN COMMITTEE ON DAMS - CBDB. Large Brazilian Spillways - An overview of Brazilian Pratice and Experience in designing and Building for Large Dams. CIGB - ICOLD. 205p. 2002.

CABRAL, J. B. P; BECEGATO, V. A; LOPES, R. M; SCOPEL, I. Estudo da erosividade e espacialização dos dados com técnicas de geoprocessamento na carta topográfica de Morrinhos-Goiás / Brasil para o período de 1971 a 2000. In: International Review of Geographical Information Science and Technology GeoFocus - ISSN: 1578-5157. N5. 1-18p. 2005.

CABRAL, J.P.C; BECEGATO.V.A. Erosividade das chuvas e sua distribuição espacial na carta topográfica de Uberlândia-MG. In: Revista de Estudos Ambientais. V7. 12p. 2005.

CACHOEIRADOURADA SOCIEDADE ANÔNIMA - CDSA. Relatório técnico (fotos). 24p. 20p. 2003.

CAMARGO, M.G. SYSGRAN para Windows: sistema de análises granulométricas. Pontal do Sul. 2 disquetes, 5 1/4. 1999.

CARVAlHO, N.O. Hidrossedimentologia Prática. CPRM e ELETROBRÁS. Rio de Janeiro, RJ. 384p. 1994.

CARVALHO, N.O. Assoreamento de reservatórios conseqüências e mitigação dos efeitos. In: IV Encontro Nacional de engenharia de Sedimentos. Santa MariaRS. Cdrom. 1-22p. 2000.

CARVALHO, N. O; FILIZOLA JR., SANTOS, P. M. C; LIMA, J. E. F. W. - Guia de avaliação de assoreamento de reservatórios. Brasília : ANEEL, 132p. 2000.

CELG - CENTRAIS ELÉTRICA DE GOiás - Usina Hidrelétrica de Cachoeira Dourada - Etapa IV Estudo de Viabilidade. 450p. 1984. 
Avaliação do estado de assoreamento do reservatório de Cachoeira Dourada (GO/MG)

João Batista Pereira Cabral, Luiz Alberto Fernandes, Iraci Scopel, Valter Antonio Becegato, Alberto Pio Fiori

COELHO,M.P. Análise do processo de assoreamento do reservatório de Americana - SP. Dissertação (Mestrado em Geociências e Meio Ambiente). Programa de Pós-Graduação em Geociências. Universidade Estadual Paulista. Campus de Rio Claro. 69p. 1993.

FOLK,R.L; WARD, W.C. Brazos river bar: a study in the significance of grain size parameters. Journal sedimetology Petrology, 27:3-27. 1957.

GOLDEN SOFTWARE: SURFER, versão 8.0. conjunto de programas. 1CD-Rom e manuais. (informações em http://www.goldensoftware.com). 1999.

GROVER, H.G; HOWARDS, C.S. The passage of turbid water through lake mead. Tran ASCE.103. 720p-736p. 1938.

ICOLD, INTERNATIONAL COMMISSION ON LARGE DAMS. Sedimentation control of reservoirs. Guidelines. Bulletin 67. Paris. 1989.

IBGE - INSTITUTO BRASILEIRO DE GEOGRAFIA E ESTATÍSTICA. Projeto Radambrasil. Ministério das Minas e Energia. Secretária geral. Levantamento de Recursos hídricos. Folha SE 22 - Goiânia. V31. Geologia, geomorfologia, pedologia. Rio de Janeiro. 1983.

KRUMBEIN,W.V Size frequency distribution of sediments. Journal of Sedimentology Petrology. 4:6577. 1934.

SURFER. Geomatemática. Texto didático 8. DGA.IGCE.UNESP/Rio Claro, 20p. 2002.

LANNA, E. A. Elementos de estatísticos e probabilidade. In: Hidrologia. Cap 4. Tucci, C.E.M. 79 -176p. 2000.

LATRUBESSE. E.M; CARVALHO,T.M; STEVAUX.J.C. Mapa geomorfológico do estado de Goiás - relatório (no prelo). 85p. 2004.
MODESTO, R.P. Uso e ocupação do solo e sua influência na formação de depósitos sedimentares e assoreamento na bacia da represa Billings. Dissertação (Mestrado em Geografia Física). Programa de Pós-Graduação em Geografia. Universidade de São Paulo. 174p. 1999.

MORRIS, G.L; FAN, J. Reservoir sedimentation handbook: design and management of dams, reservoir, and watersheds for sustainable use. New York, McGraw-Hill. 805p. 1997.

PONÇANO, W.L; GIMENEZ, A.F.; FÚLFARO, V.J. Sedimentação atual na Baía de Sepetiba, Estado do Rio de Janeiro: contribuição à avaliação de viabilidade geotécnica da implantação de um porto. Anais I Congresso Brasileiro de Geologia de Engenharia, vol. 2 ABGE, Rio de Janeiro, 111-139p. 1976.

SCOPEL, I., ASSUNÇÃO.H.F. Erosividade no estado de Goiás. In: XI Congresso Brasileiro de Agrometerologia. II Reunião Latino America de Agrometerologia. Anais - cdrom. Florianópolis - SC, 1-9p, 1999.

SECTEC - SUPERINTENDÊNCIA DE CIÊNCIAS E TECNOLOGIA DE GOIÁS. Bacia hidrográfica do Rio Paranaíba. Capturado em agosto de 2000. Online. Disponível em: $\leq \mathrm{http}: / /$ www.sectec.go.gov.br $>$. Acesso em 16 de agosto de 2000.

SIG-GOIÁS (SISTEMA DE INFORMAÇÃO GEOGRÁFICA DE GOIÁS): Solos de Goiás. CDROM. 2003.

SIEG (Sistema de informações estatísticas e geográficas de Goiás). [online] <http:www.sieg.go.gov.br>. 2004.

SOUSA, S.P. Proposta metodológica para estimativa de assoreamento de reservatórios: Estudo de caso do sistema Manso.1996, 147 f. Dissertação (Mestrado em Engenharia). Programa de Pós-Graduação em Engenharia Civil. Universidade Federal de Viçosa. Viçosa, 1996.

Sociedade \& Natureza, Uberlândia, 21 (1): 97-119, ABR. 2009 
STOKES, G.G On the effect of the internal friction of fluids on the motion of pendulum. Trans Cambridge Philos. Soc. 9. Parte 2, 8-106p. 1851.

STRAND, ROBERT I. Reservoir Sedimentation - In: Design of Small Dams. US Bureau of Reclamation. Washington, DC.767-795p. 1974.

SUGUIO, K. Introdução a Sedimentologia. Editora da Universidade de São Paulo, São Paulo - SP. 317 p.1973.

VILHENA,R.M; ROIG.H.L; MENESES.P.R Determinação do assoreamento de reservatório utilizando técnicas de geoprocessamento, o caso do reservatório de Funil - RJ.In: XI Simpósio Brasileiro de Sensoriamento Remoto (SBSR) (cdrom). Belo Horizonte - MG. 2649-2651p. 2003.

WENTWORTH,C.K. A scale of grade and class terms for clastic sediments. Journal of Geology.30: 377392p. 1922. 